\title{
Proteomic profiling of the mouse diaphragm and refined mass spectrometric analysis of the dystrophic phenotype
}

\author{
Sandra Murphy ${ }^{1,2} \cdot$ Margit Zweyer $^{3} \cdot$ Maren Raucamp $^{3} \cdot$ Michael Henry $^{4} \cdot$ Paula Meleady $^{4} \cdot$ Dieter Swandulla $^{3}$. \\ Kay Ohlendieck ${ }^{1}$ (D)
}

Received: 12 November 2018 / Accepted: 8 March 2019 / Published online: 19 March 2019

(c) Springer Nature Switzerland AG 2019

\begin{abstract}
The diaphragm is a crucial muscle involved in active inspiration and whole body homeostasis. Previous biochemical, immunochemical and cell biological investigations have established the distribution and fibre type-specific expression of key diaphragm proteins. Building on these findings, it was of interest to establish the entire experimentally assessable diaphragm proteome and verify the presence of specific protein isoforms within this specialized subtype of skeletal muscle. A highly sensitive Orbitrap Fusion Tribrid mass spectrometer was used for the systematic identification of the mouse diaphragmassociated protein population. Proteomics established 2925 proteins by high confidence peptide identification. Bioinformatics was used to determine the distribution of the main protein classes, biological processes and subcellular localization within the diaphragm proteome. Following the establishment of the respiratory muscle proteome with special emphasis on protein isoform expression in the contractile apparatus, the extra-sarcomeric cytoskeleton, the extracellular matrix and the excitation-contraction coupling apparatus, the mass spectrometric analysis of the diaphragm was extended to the refined identification of proteome-wide changes in X-linked muscular dystrophy. The comparative mass spectrometric profiling of the dystrophin-deficient diaphragm from the $m d x-4 c v$ mouse model of Duchenne muscular dystrophy identified 289 decreased and 468 increased protein species. Bioinformatics was employed to analyse the clustering of changes in protein classes and potential alterations in interaction patterns of proteins involved in metabolism, the contractile apparatus, proteostasis and the extracellular matrix. The detailed pathoproteomic profiling of the $m d x-4 c v$ diaphragm suggests highly complex alterations in a variety of crucial cellular processes due to deficiency in the membrane cytoskeletal protein dystrophin.
\end{abstract}

Keywords Diaphragm $\cdot$ Duchenne muscular dystrophy $\cdot$ Dystrophin $\cdot$ Dystrophinopathy $\cdot M d x-4 c v$ mouse $\cdot$ Skeletal muscle proteome

\section{Introduction}

Electronic supplementary material The online version of this article (https://doi.org/10.1007/s10974-019-09507-z) contains supplementary material, which is available to authorized users.

Kay Ohlendieck

kay.ohlendieck@mu.ie

1 Department of Biology, Maynooth University, National University of Ireland, Maynooth, Co. Kildare, Ireland

2 Newcastle Fibrosis Research Group, Institute of Cellular Medicine, Faculty of Medical Sciences, Newcastle University, Newcastle upon Tyne, UK

3 Institute of Physiology II, University of Bonn, 53115 Bonn, Germany

4 National Institute for Cellular Biotechnology, Dublin City University, Dublin 9, Ireland
In mammalians, bronchoalveolar function and efficient gasexchange in the lungs is intrinsically coupled to the contractile activity of the diaphragm (Kocjan et al. 2017). The specialized diaphragm muscle, which anatomically separates the abdominal and thoracic cavity, is essential for respiration and acts as the primary contractile force of active inspiration. In addition, the diaphragm is involved in the functioning of the vascular and lymphatic systems, supports postural control via stabilisation of the lumbar spine during loading work, and contributes to essential gastroesophageal functions and its reflux barrier (Bordoni and Zanier 2013). The specialized task of continuous contractile performance by the diaphragm is reflected by the physiological resistance to fatigue, the high density of capillaries and an elevated 
aerobic oxidative capacity. Pathological changes in the diaphragm muscle have devastating effects on the overall physiological homeostasis in the body. In Duchenne muscular dystrophy, an X-linked neuromuscular disorder with a highly progressive muscle wasting aetiology, the diaphragm is severely affected and causes respiratory deficiencies (Khirani et al. 2014).

With the rapid advances of systems biological approaches in the field of skeletal muscle biology (Smith et al. 2013), it is now possible to routinely determine large-scale changes at the level of the transcriptome, proteome and metabolome in adapting or diseased muscle tissues. Although mass spectrometry-based proteomics has been widely applied to the comparative analysis of the diaphragm (Matsumura et al. 2013; Sollanek et al. 2017; Kelley et al. 2018), the establishment of a comprehensive proteomic databank for diaphragm has not yet been fully realized. However, using liquid chromatography and/or gel electrophoretic techniques (Murphy et al. 2016), general skeletal muscle proteomics has made enormous progress in the systematic cataloguing of assessable muscle protein populations from muscle cell lines, as well as select muscles from humans and animal models (Dowling et al. 2016; Capitanio et al. 2017; Gonzalez-Freire et al. 2017), and has identified over 10,000 muscle-associated protein species (Højlund et al. 2008; Parker et al. 2009; Deshmukh et al. 2015). The complexity of bioenergetic processes and mitochondrial specialization in skeletal muscles was verified by single fibre proteomics (Murgia et al. 2015).

Building on these findings from biochemical profiling studies of skeletal muscle tissue, in this report we describe the proteomic and bioinformatic analysis of the adult mouse diaphragm, using an Orbitrap Fusion Tribrid mass spectrometer, with special focus on protein isoform expression in the contractile apparatus, the extra-sarcomeric cytoskeleton, the extracellular matrix and the excitation-contraction coupling apparatus. Following the establishment of the assessable diaphragm proteome, a comparative approach was used for the refined identification of proteomic alterations in the $m d x-4 c v$ mouse model of Duchenne muscular dystrophy. X-linked muscular dystrophy is due to primary abnormalities in the Dmd gene and represents the most frequently inherited neuromuscular disorder of early childhood (Guiraud et al. 2015). Dystrophinopathies are characterized by a complex multi-system pathology including progressive fibre degeneration, fatty tissue replacement and reactive myofibrosis (Ohlendieck and Swandulla 2017), as well as severe impairments of ion homeostasis and cellular signalling mechanisms (Allen et al. 2016) and sterile inflammation (Tidball et al. 2018).

In addition, cardiac impairment and respiratory muscle decline are hallmarks of X-linked muscular dystrophy (Khirani et al. 2014; Hor et al. 2018). Diaphragm muscle weakness is intrinsically involved in sleep disordered breathing in Duchenne patients, especially when the diaphragm has to provide most of the ventilation during the rapid eye movement sleep phase of maximal muscle hypotonia (LoMauro et al. 2017). Importantly, the diaphragm in the $m d x$ mouse model of dystrophinopathy shows a pathological pattern of fibre degeneration, myofibrosis, inflammation and severe functional deficit comparable to that seen in Duchenne patients (Stedman et al. 1991; Ishizaki et al. 2008; Coirault et al. 2003), making $m d x$-type diaphragm muscles highly suitable for studying the pathobiochemical consequences of the almost complete loss of the membrane cytoskeletal protein dystrophin and its associated glycoprotein complex (Murphy and Ohlendieck 2015). The systematic analysis of dystrophinopathy-associated changes presented here suggests drastic changes in the abundance and interaction patterns of a large variety of diaphragm proteins involved in energy metabolism, the excitation-contraction-relaxation cycle, proteostasis and the organization of the extracellular matrix.

\section{Experimental section}

\section{Materials}

A variety of general analytical grade reagents and materials were used for the proteomic profiling of mouse diaphragm muscle, as well as the comparative mass spectrometric survey of diaphragm preparations from wild type versus dystrophic $m d x-4 c v$ mice. These reagents were obtained from GE Healthcare (Little Chalfont, Buckinghamshire, UK), Bio-Rad Laboratories (Hemel-Hempstead, Hertfordshire, UK) and Sigma Chemical Company (Dorset, UK). Sequencing grade modified trypsin was purchased from Promega (Madison, WI, USA) and Whatman nitrocellulose transfer membranes came from Invitrogen (Carlsbad, CA, USA). The chemiluminescence substrate and protease inhibitors were obtained from Roche Diagnostics (Mannheim, Germany). The primary antibodies to dystrophin and carbonic anhydrase isoform CA3 were from Leica Biosystems, Wetzlar, Germany (antibody NCL-DYS1 [clone Dy8/6C5]) and Abcam, Cambridge, UK (antibody ab118428), respectively. For immunofluorescence microscopy, normal goat serum and anti-mouse and anti-rabbit IgG (Alexa Fluor 488 and Alexa Fluor 568) were purchased from Molecular Probes, Life Technologies (Darmstadt, Germany) and Jackson ImmunoResearch (West Grove, PA, USA), respectively. The embedding medium Fluoromount $\mathrm{G}$ was from Southern Biotech (Birmingham, AL, USA). 


\section{Genetic $m d x-4 c v$ mouse model of Duchenne muscular dystrophy}

The $m d x-4 c v$ mouse model is one of four chemical variants of the spontaneous $m d x$ mutant, generated on the C57/BL6 background by chemical mutagenesis using N-ethyl-nitrosourea (Chapman et al. 1989). The resulting $\mathrm{C}$ to $\mathrm{T}$ transition in exon 53 of the Dmd gene introduces a premature stop codon. For the generation of a proteomic map of wild type diaphragm and for the identification of global proteomic alterations in the dystrophin-deficient diaphragm, whole diaphragms from 10-month old control C57/BL6 mice and age-matched $m d x-4 c v$ mice were obtained from the Bioresource Unit of the University of Bonn. Mice were kept under standard conditions and all procedures adhered to German legislation on the use of animals in experimental research. The animals were sacrificed by cervical dislocation and diaphragms were carefully dissected and quick-frozen in liquid nitrogen. Samples were transported to Maynooth University in accordance with the Department of Agriculture (animal by-product register number 2016/16 to the Department of Biology, National University of Ireland, Maynooth) on dry ice and stored at $-80{ }^{\circ} \mathrm{C}$ prior to analysis.

\section{Preparation of diaphragm homogenates from wild type versus dystrophic mice}

Following an optimization phase for protein extraction from diaphragm homogenates, proteomic analyses were carried out with protein populations derived from the preparation of whole diaphragms (with an average weight of $150 \mathrm{mg}$ ). Tissue specimens from 10-month old wilde type mice $(n=4)$ and age-matched $m d x-4 c v$ mice $(\mathrm{n}=4)$ were finely chopped and homogenised in $1 \mathrm{ml}$ of lysis buffer (6M urea, $2 \mathrm{M}$ thiourea, supplemented with a protease inhibitor cocktail), using a hand-held IKA T10 Basic Homogeniser (IKA Labortechnik, Staufen, Germany). Homogenates were kept on ice for $2 \mathrm{~h}$ and were subsequently centrifuged at $14,000 \times \mathrm{g}$ for $20 \mathrm{~min}$ at $4{ }^{\circ} \mathrm{C}$ (Holland et al. 2015a). The protein containing supernatant was removed and used for comparative proteomic analysis.

\section{Sample preparation for label-free liquid chromatography mass spectrometry}

Protein concentrations were determined by the Bradford method (Bradford 1976) and concentrations were then equalised with lysis buffer. $30 \mu \mathrm{g}$ of protein was processed by the FASP (filter aided sample preparation) method (Wiśniewski et al. 2009) using a trypsin to protein ratio of 1:25 (protease:protein). Following overnight digestion and elution of peptides from the spin filter, $2 \%$ trifluoroacetic acid (TFA) in $20 \%$ acetonitrile (ACN) was added to the filtrates [3:1 (v/v) dilution]. The peptides were then purified using Pierce C18 spin columns from Thermo Fisher Scientific (Dublin, Ireland), dried through vacuum centrifugation and re-suspended in mass spectrometry loading buffer. Peptides were vortexed, sonicated and briefly centrifuged at $14,000 \times g$ and the supernatant transferred to mass spectrometry vials for label-free LC-MS/MS analysis.

\section{Label-free liquid chromatography mass spectrometry}

As recently outlined in detail (Murphy et al. 2018), reversephased capillary high pressure liquid chromatography was carried out using the UltiMate 3000 nano system (Thermo Scientific) coupled directly in-line with the Thermo Orbitrap Fusion Tribrid Mass Spectrometer (Thermo Scientific). The digested samples were loaded onto the trapping column (PepMap100, C18, $300 \mu \mathrm{m} \times 5 \mathrm{~mm}$ ) at a flow rate of $25 \mu \mathrm{L} /$ min with $2 \%(\mathrm{v} / \mathrm{v})$ acetonitrile $(\mathrm{ACN}), 0.1 \%(\mathrm{v} / \mathrm{v})$ trifluoroacetic acid (TFA) for $3 \mathrm{~min}$ before being resolved onto an analytical column (Acclaim PepMap 100, $75 \mu \mathrm{m} \times 50 \mathrm{~cm}$, $3 \mu \mathrm{m}$ bead diameter column). Peptides were eluted using the following binary gradient; solvent $\mathrm{A}(0.1 \%(\mathrm{v} / \mathrm{v})$ formic acid in LC-MS grade water) and 2-27.5\% solvent B (80\% (v/v) $\mathrm{ACN}, 0.08 \%(\mathrm{v} / \mathrm{v})$ formic acid in LC-MS grade water) for $110 \mathrm{~min}$ at a flow rate of $300 \mathrm{~nL} / \mathrm{min}$. For peptide ionization, a voltage of $1.9 \mathrm{kV}$ was applied and a capillary temperature of $320{ }^{\circ} \mathrm{C}$ was used. Data-dependent acquisition with full scans in the $375-1500 \mathrm{~m} / \mathrm{z}$ range was performed using an Orbitrap mass analyser with a resolution of 120,000 (at $\mathrm{m} / \mathrm{z} 200$ ), a targeted automatic gain control (AGC) value of $4 \mathrm{E}+05$ and a maximum injection time of $50 \mathrm{~ms}$. The number of selected precursor ions for fragmentation was determined by the top-speed acquisition algorithm. Selected precursor ions were isolated in the Quadrupole with an isolation width of 1.6 Da. Peptides with a charge state of $2+$ to $6+$ were analysed and a dynamic exclusion was applied after 60 s. Precursor ions were fragmented using higher energy collision-induced dissociation (HCD) with a normalized collision energy of $28 \%$, and resulting MS/MS ions were measured in the linear ion trap. The typical MS/MS scan conditions were as follows: a targeted AGC value of $2 \mathrm{E}+04$ and a maximum fill time of $35 \mathrm{~ms}$.

\section{Protein profiling by label-free liquid chromatography tandem mass spectrometry}

Qualitative data analysis was used to characterise the proteome of wild type diaphragm muscle. MS raw files from label-free liquid chromatography tandem mass spectrometry (LC-MS/MS) analysis were processed using the Proteome Discoverer 1.4 (Thermo Fisher Scientific) software with Sequest HT as the search engine and the Mus musculus 
UniProtKB-SwissProt sequence database. The following search parameters were used for protein identification: (1) peptide mass tolerance set to $10 \mathrm{ppm}$, (2) MS/MS mass tolerance set to $0.6 \mathrm{Da}$, (3) up to two missed cleavages, (4) carbamidomethylation set as a fixed modification and (5) methionine oxidation set as a variable modification. Peptides were filtered using a minimum XCorr score of 1.5 for +1 , 2.0 for $+2,2.25$ for +3 and 2.5 for +4 charge states, with peptide probability set to high confidence.

Progenesis QI for Proteomics software (version 3.1; Non-Linear Dynamics, a Waters company, Newcastle upon Tyne, UK) was used for the quantitative analysis of diaphragm from wild-type versus $m d x-4 c v$ mice. To account for potential drifts in retention time, all runs were aligned to a reference run. The following settings were used to filter peptide features: (1) peptide features with ANOVA $\leq 0.05$ between experimental groups, (2) mass peaks with charge states from +1 to +4 and (3) greater than one isotope per peptide (Murphy et al. 2018). A Mascot generic file (mgf) was generated from all exported MS/MS spectra which was used for peptide and protein identification via Proteome Discoverer 2.1 (Thermo Scientific) using Sequest HT against the UniProtKB-SwissProt Mus musculus database. The following search parameters were used: (1) peptide mass tolerance set to $10 \mathrm{ppm}$, (2) MS/MS mass tolerance set to 0.6 Da, (3) up to two missed cleavages, (4) carbamidomethylation set as a fixed modification and (5) methionine oxidation set as a variable modification. For re-importation back into Progenesis LC-MS software as a PepXML file only highly confident peptides with a FDR of $\leq 0.01$ as determined by Percolator validation in Proteome Discoverer were allowed (O'Sullivan et al. 2017). The following criteria were applied to assign proteins as positively identified: (1) an ANOVA score between experimental groups of $\leq 0.05$, (2) proteins with $\geq 2$ unique peptides matched and (3) a fold change $\geq$ 1.5 .

A heat map illustrating protein abundances for statistically significant differentially abundant proteins with a fold change of 2 or more was designed using Perseus software. The normalised abundances of differentially abundant proteins determined using Progenesis QI for Proteomics were loaded as a txt file into Perseus and the data was $\log 2$ transformed. Hierarchical clustering was then performed on $\mathrm{Z}$-score normalised intensity values by clustering both samples and proteins using Euclidean distance and average linkage.

\section{Bioinformatics analysis}

In order to group identified diaphragm proteins based on their protein class and to identify potential protein-protein interaction patterns, publically available bioinformatics software programmes were employed. Bioinformatics analysis was performed with datasets from both the assessable total mouse diaphragm proteome and identified proteins with a changed concentration in the dystrophic $m d x-4 c v$ diaphragm. The programs used were the DAVID (version 6.8.) bioinformatics resource for the identification of enriched gene ontology terms (https://david.ncifcrf.gov), the PANTHER database of protein families (Mi et al. 2017; http://pantherdb. org/) and the STRING database of known and putative protein interactions that include both direct physical and indirect functional protein associations (Szklarczyk et al. 2017; http://string-db.org/). KEGG colour pathway analysis of the dystrophic $m d x-4 c v$ diaphragm was carried out with a focus on proteins involved in oxidative phosphorylation using the Kyoto Encyclopedia of Genes and Genomes databank (Kanehisa et al. 2017; https://www.genome.jp/kegg).

\section{Comparative histology and immunofluorescence microscopy}

Characteristic histopathological changes and reduction of the dystrophin isoform Dp427-M in the diaphragm of the genetic $m d x-4 c v$ mouse model of Duchenne muscular dystrophy was carried out with routine histological haematoxylin and eosin staining and immunofluorescence microscopy, as previously described in detail (Murphy et al. 2019b). Freshly dissected diaphragm muscle specimens from 12-month $m d x-4 c v$ versus wild type mice were quick-frozen in liquid nitrogen-cooled isopentane and $10 \mu \mathrm{m}$ sections cut in a cryostat. For dystrophin immuno-staining, unfixed cryosections were boiled in phosphate-buffered saline for $5 \mathrm{~min}$. Primary antibodies to dystrophin were diluted appropriately in phosphate-buffered saline for overnight incubation at $4{ }^{\circ} \mathrm{C}$. Tissue specimens were then washed and incubated with a secondary fluorescently-labelled anti-mouse antibody for $45 \mathrm{~min}$ at room temperature. Fluorescent labeling of tissue sections for carbonic anhydrase was carried out in a similar manner, but with secondary anti-rabbit antibodies. Nuclei were counter-stained with $1 \mu \mathrm{g} / \mathrm{ml}$ bis-benzimide Hoechst 33342. Antibody-labelled muscle tissue sections were embedded in Fluoromount $\mathrm{G}$ medium and viewed under a Zeiss Axioskop 2 epifluorescence microscope equipped with a digital Zeiss AxioCam HRc camera (Carl Zeiss Jena GmbH, Jena, Germany).

\section{Results}

\section{Proteomic profiling of the mouse diaphragm muscle}

With the help of an Orbitrap Fusion Tribrid mass spectrometer, the assessable proteome of 10-month old mouse diaphragm muscle was catalogued. The proteomic screening approach identified 2925 diaphragm-associated proteins 
using multi-consensus data files from the analysis of eight separate mass spectrometric sample runs (four biological repeats and two technical repeats) consisting of high confidence peptides that were filtered based on Xcorr values. The data underlying the cataloguing of the diaphragm muscle has been deposited to the Open Science Framework (17 files under the project title 'Proteomic profile of mouse diaphragm muscle'; https://osf.io/mxfc9/?view_only=9a321 60f876f42bb813da48867457d6c; Date created: 2018-0723; project description: the data here is 16 raw files from the LC-MS/MS analysis of wild-type and $m d x-4 c v$ crude diaphragm homogenates (four biological repeats, two technical repeats). Also shown is the Proteome Discoverer multiconsensus report of the eight wild type diaphragm mass spectrometry raw files).

The quality of the proteomic findings was demonstrated by the wide range of identified proteins and the high percentage of sequence coverage of typical skeletal muscleassociated protein species. The list of identified proteins ranged from very small proteins $(60 \mathrm{~S}$ ribosomal protein L38 of $8 \mathrm{kDa} ; 45.7 \%$ coverage; 4 unique peptides) to small proteins (muscle-specific myosin light chain MLC1/3 of $21 \mathrm{kDa} ; 90.4 \%$ coverage; 14 unique peptides) to mediumsize proteins $\left(\mathrm{Ca}^{2+}\right.$-ATPase isoform SERCA1 of $109 \mathrm{kDa}$;
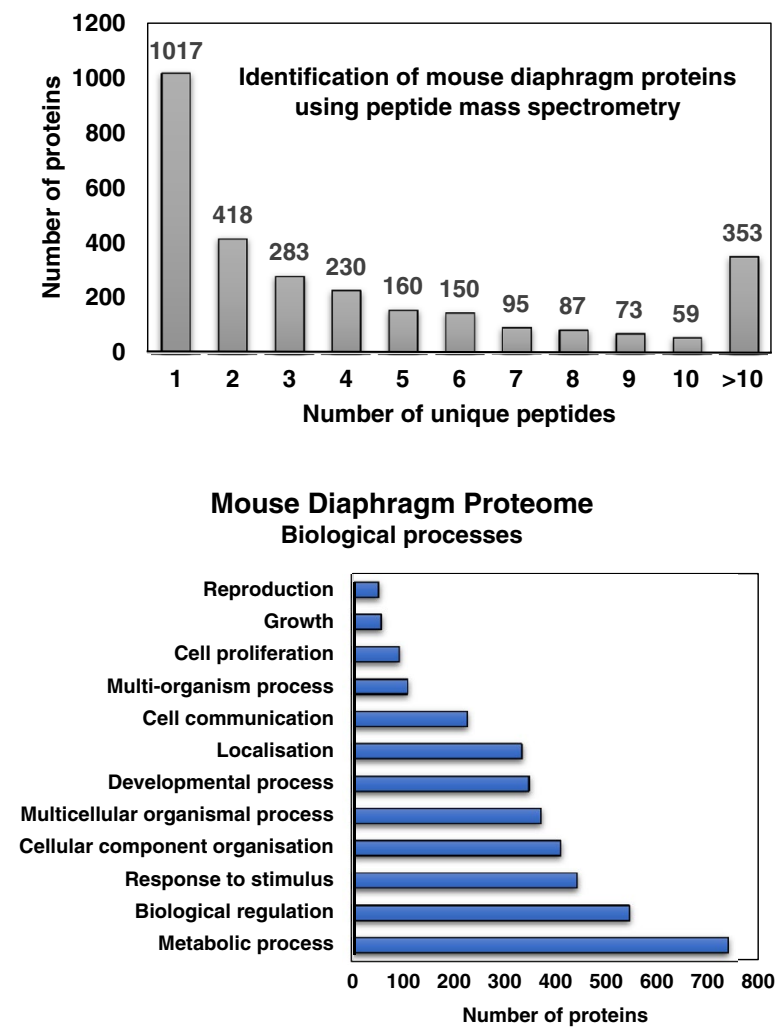

Fig. 1 Proteomic profile of the mouse diaphragm muscle. Shown is an overview of the identification of mouse diaphragm proteins using peptide mass spectrometry, as well as findings from the bioinformat-
$47.9 \%$ coverage; 35 unique peptides) to large proteins (fulllength dystrophin isoform Dp427-M of $426 \mathrm{kDa} ; 32.5 \% \mathrm{cov}$ erage; 90 unique peptides) to giant muscle proteins (titin of $3904 \mathrm{kDa} ; 53.1 \%$ coverage; 1299 unique peptides).

In below sections, individual tables list the proteomic identification of select markers of the contractile apparatus and its associated sarcomeric structures, the extra-sarcomeric cytoskeleton including the dystrophin-glycoprotein complex, the extracellular matrix and the excitation-contraction coupling and ion-handling apparatus. Pathobiochemical changes in these cellular structures and mechanisms are of central importance for our understanding of the molecular pathogenesis of neuromuscular diseases, and will be discussed in this report in relation to X-linked muscular dystrophy.

\section{Bioinformatics analysis of the assessable mouse diaphragm}

Information on the total number of identified diaphragm proteins in relation to their sequence coverage by numbers of unique peptides is provided in Fig. 1. Bioinformatics analysis was carried out with 1,908 proteins that had been identified by 2 or more unique peptides. The overview of the

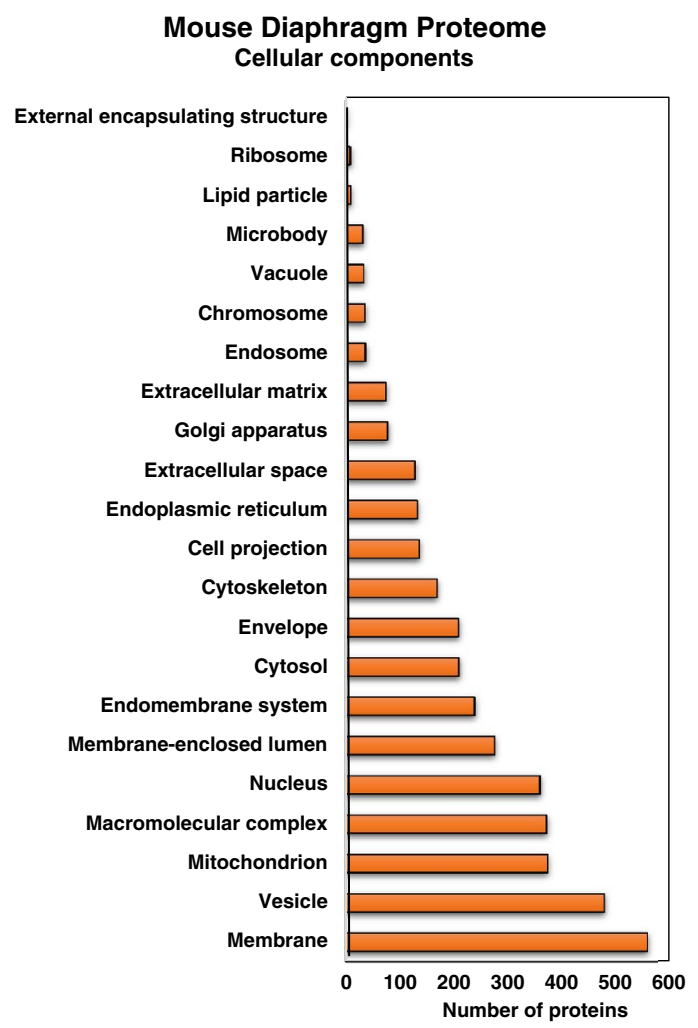

ics analysis of the distribution of biological processes and the subcellular localization of identified diaphragm proteins 
distribution of individual protein members of the assessable diaphragm proteome shows a broad spectrum of involvements in biological processes and a variety of localizations in subcellular structures. A large number of diaphragm proteins was shown to be functionally linked to metabolism, regulation, signalling and cellular organization, and being located in various membranes, a large number of organelles including mitochondria, sarcoplasmic reticulum, Golgi apparatus and endosomes, as well as macromolecular complexes, cytoskeletal systems and the extracellular matrix (Fig. 1).

The PANTHER analysis of the mouse diaphragm proteome, shown in Fig. 2, gives an overview of the 25 most common protein classes present in the proteome of this contractile tissue. The classification revealed that a large number of identified diaphragm proteins belong to the class of hydrolases, nucleic acid binding proteins, oxidoreductases, transferases, enzyme modulators and cytoskeletal components.

\section{Proteomic map of the contractile apparatus}

As listed in detail in Table 1, the proteomic profiling of the wild type mouse diaphragm established the presence of the main isoforms of myosin heavy chain, including MyHC2x, MyHC-3, MyHC-2b, MyHC-slow and MyHC-perinatal, the main isoforms of myosin light chain, muscle MLC kinase and myosin-binding proteins. Key components of the actin filament were also clearly identified by proteomics, including $\alpha$-actin, the troponin complex, tropomyosins and F-actin-capping protein. Major constituents of the Z-disk complex, the M-band and the titin filament were shown to be present in the diaphragm extracts.

\section{Proteomic map of the extra-sarcomeric cytoskeletal network}

The main components of the extra-sarcomeric network of cytoskeletal proteins have been identified by the proteomic screening of mouse diaphragm and are listed in Table 2. This includes the main protein classes involved in the structural stabilisation and maintenance of intermediate filaments, the intracellular actin cytoskeleton and membrane-associated cytoskeletal systems. The core members of the dystrophin-glycoprotein complex were shown to be present in the analysed diaphragm extract. This included the full-length muscle dystrophin isoform Dp427-M and the members of the $\alpha / \beta$-dystroglycan subcomplex, as well as $\alpha / \beta / \gamma / \delta$ sarcoglycans, syntrophin and dystrobrevin.

\section{Proteomic map of the extracellular matrix}

The mass spectrometric survey of mouse diaphragm extracts presented in this study identified various laminins and the basement membrane-specific heparan sulfate proteoglycan core protein, both major components of the basal lamina. The main structural protein of the extracellular matrix, collagen, was confirmed to exist in a plethora of isoform
Fig. 2 Summary of protein classes in the mouse diaphragm muscle. The bioinformatics software programme PANTHER was employed to summarize the clustering of protein classes based on the mass spectrometric analysis of wild type mouse diaphragm

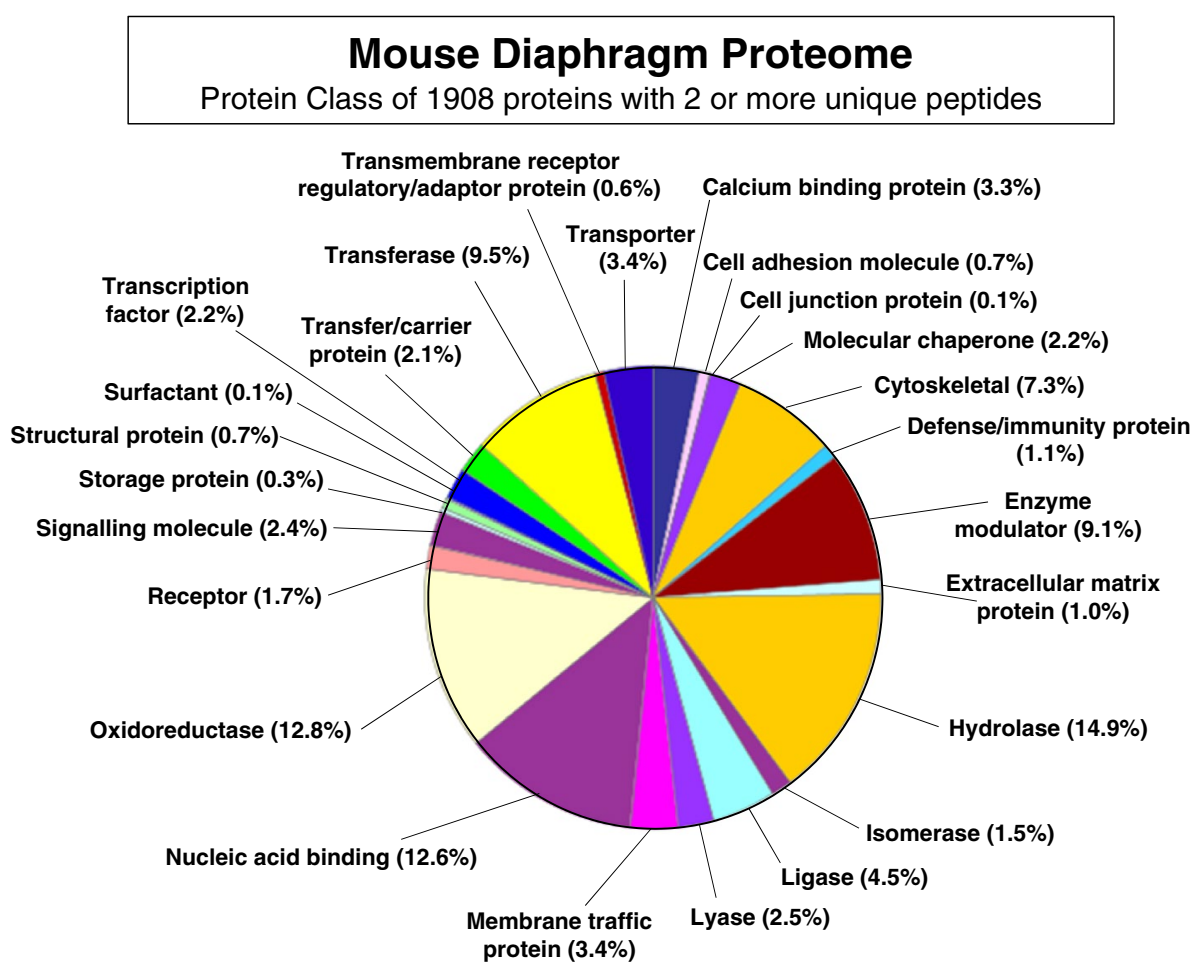


Table 1 Proteomic profile of the contractile apparatus and associated sarcomeric proteins of mouse diaphragm muscle

\begin{tabular}{|c|c|c|c|c|c|}
\hline Accession & Protein name & Gene name & Coverage $\%$ & Unique Peptides & Peptides \\
\hline Q5SX40 & Myosin-1, MyHC-2x & Myh1 & 69.57 & 46 & 185 \\
\hline P13541 & Myosin-3, MyHC-3 & Myh3 & 26.55 & 5 & 71 \\
\hline Q5SX39 & Myosin-4, MyHC-2b & Myh4 & 66.32 & 34 & 168 \\
\hline Q91Z83 & Myosin-7, MyHC-slow & Myh7 & 65.27 & 100 & 153 \\
\hline P13542 & Myosin-8, MyHC-perinatal & Myh8 & 47.96 & 6 & 127 \\
\hline P05977 & Myosin light chain MLC1/MLC3 & Myl1 & 90.43 & 14 & 18 \\
\hline P97457 & Myosin light chain MLC2, muscle & Mylpf & 86.39 & 15 & 15 \\
\hline P51667 & Myosin light chain MLC2, slow & Myl2 & 86.14 & 14 & 14 \\
\hline P09542 & Myosin light chain MLC3, slow & Myl3 & 78.43 & 13 & 17 \\
\hline Q8VCR8 & Myosin light chain kinase 2 & Mylk2 & 22.84 & 7 & 8 \\
\hline Q5XKE0 & Myosin-binding protein MyBP-C & Mybpc2 & 52.38 & 49 & 49 \\
\hline P70402 & Myosin-binding protein MyPB-H & Mybph & 18.43 & 5 & 5 \\
\hline P68134 & Actin, alpha skeletal muscle & Acta1 & 73.74 & 3 & 26 \\
\hline P20801 & Troponin TnC, muscle & Tnnc2 & 52.50 & 6 & 7 \\
\hline P19123 & Troponin TnC, slow muscle & Tnnc1 & 47.20 & 6 & 6 \\
\hline O88346 & Troponin TnT, slow muscle & Tnnt1 & 45.80 & 9 & 12 \\
\hline Q9QZ47 & Troponin TnT, fast muscle & Tnnt3 & 43.93 & 14 & 17 \\
\hline Q9WUZ5 & Troponin TnI, slow muscle & Tnni1 & 36.36 & 7 & 7 \\
\hline P13412 & Troponin TnI, fast muscle & Tnni2 & 32.42 & 8 & 8 \\
\hline P58771 & Tropomyosin, alpha-1 & Tpm1 & 67.61 & 3 & 31 \\
\hline P58774 & Tropomyosin, beta & Tpm2 & 69.72 & 5 & 28 \\
\hline P21107 & Tropomyosin, alpha-3 & Tpm3 & 64.56 & 7 & 27 \\
\hline Q6IRU2 & Tropomyosin, alpha-4 & Tpm4 & 39.11 & 8 & 12 \\
\hline Q7TPR4 & Alpha-actinin-1 & ACTN1 & 39.91 & 14 & 32 \\
\hline Q9JI91 & Alpha-actinin-2 & Actn2 & 75.95 & 39 & 57 \\
\hline O88990 & Alpha-actinin-3 & ACTN3 & 66.33 & 37 & 51 \\
\hline P57780 & Alpha-actinin-4 & Actn4 & 55.92 & 25 & 39 \\
\hline P47753 & F-actin-capping protein, alpha-1 & Capza1 & 25.17 & 2 & 4 \\
\hline P47754 & F-actin-capping protein, alpha- 2 & Capza2 & 58.39 & 8 & 10 \\
\hline P47757 & F-actin-capping protein, beta & Capzb & 37.91 & 11 & 11 \\
\hline Q8VHX6 & Filamin-C, muscle & Flnc & 53.01 & 91 & 102 \\
\hline Q02357 & Ankyrin-1 & Ank1 & 12.04 & 6 & 12 \\
\hline Q8C8R3 & Ankyrin-2 & Ank2 & 1.69 & 3 & 5 \\
\hline O70548 & Telethonin & Tcap & 17.96 & 3 & 3 \\
\hline Q62234 & Myomesin-1 & Myom1 & 62.33 & 2 & 88 \\
\hline A2ABU4 & Myomesin-3 & Myom3 & 50.03 & 54 & 54 \\
\hline P49813 & Tropomodulin-1 & Tmod1 & 32.59 & 7 & 8 \\
\hline Q9JLH8 & Tropomodulin-4 & Tmod4 & 40.00 & 11 & 12 \\
\hline Q9JK37 & Myozenin-1 & Myoz1 & 75.00 & 12 & 12 \\
\hline Q9JJW5 & Myozenin-2 & Myoz2 & 70.83 & 15 & 15 \\
\hline Q8R4E4 & Myozenin-3 & Myoz3 & 36.73 & 6 & 6 \\
\hline Q5DTJ9 & Myopalladin & Mypn & 11.63 & 13 & 13 \\
\hline O70373 & Xin actin-binding protein 1 & Xirp1 & 12.75 & 10 & 10 \\
\hline Q4U4S6 & Xin actin-binding protein 2 & Xirp2 & 4.57 & 11 & 11 \\
\hline A2ASS6 & Titin & Tnt & 53.08 & 1299 & 1451 \\
\hline Q80XB4 & Nebulin-related-anchoring protein & Nrap & 16.01 & 22 & 22 \\
\hline A2AAJ9 & Obscurin & Obscn & 31.13 & 157 & 157 \\
\hline
\end{tabular}


Table 2 Proteomic map of the dystrophin complex and the extra-sarcomeric cytoskeletal network from diaphragm muscle

\begin{tabular}{|c|c|c|c|c|c|}
\hline Accession & Protein name & Gene name & Coverage $\%$ & $\begin{array}{l}\text { Unique } \\
\text { peptides }\end{array}$ & Peptides \\
\hline P11531 & Dystrophin, Dp427-M & Dmd & 32.46 & 90 & 90 \\
\hline Q62165 & Dystroglycan, alpha/beta & Dag1 & 7.61 & 6 & 6 \\
\hline P82350 & Sarcoglycan, alpha & Sgca & 20.41 & 6 & 6 \\
\hline P82349 & Sarcoglycan, beta & Sgcb & 29.38 & 7 & 7 \\
\hline P82348 & Sarcoglycan, gamma & Sgcg & 21.31 & 4 & 4 \\
\hline P82347 & Sarcoglycan, delta & Sgcd & 24.91 & 6 & 6 \\
\hline Q61234 & Syntrophin, alpha-1 & Snta1 & 34.59 & 10 & 10 \\
\hline Q61235 & Syntrophin, beta- 2 & Sntb2 & 5.19 & 3 & 3 \\
\hline Q9D2N4 & Dystrobrevin, alpha & Dtna & 13.06 & 6 & 6 \\
\hline P20152 & Vimentin & Vim & 72.96 & 30 & 36 \\
\hline P31001 & Desmin & Des & 72.07 & 28 & 33 \\
\hline Q64727 & Vinculin & $\mathrm{Vcl}$ & 46.90 & 38 & 38 \\
\hline P68134 & Actin, alpha skeletal muscle & Acta1 & 73.74 & 3 & 26 \\
\hline P62737 & Actin, aortic smooth muscle & Acta2 & 73.74 & 3 & 25 \\
\hline P60710 & Actin, cytoplasmic 1 & Actb & 59.20 & 6 & 20 \\
\hline P16546 & Spectrin alpha, non-erythrocytic 1 & Sptan1 & 46.94 & 83 & 84 \\
\hline Q62261 & Spectrin beta, non-erythrocytic 1 & Sptbn1 & 37.11 & 61 & 63 \\
\hline P08032 & Spectrin alpha, erythrocytic 1 & Spta1 & 18.47 & 30 & 31 \\
\hline P15508 & Spectrin beta chain, erythrocytic & Sptb & 31.06 & 47 & 49 \\
\hline Q9QXS1 & Plectin, isoform PLEC-1D & Plec & 53.82 & 213 & 213 \\
\hline Q70IV5 & Synemin & Synm & 41.46 & 37 & 37 \\
\hline P05213 & Tubulin, alpha-1B & Tuba1b & 50.55 & 2 & 17 \\
\hline P05214 & Tubulin, alpha-3 & Tuba3a & 42.44 & 1 & 14 \\
\hline P68368 & Tubulin, alpha-4A & Tuba4a & 46.43 & 3 & 16 \\
\hline Q9JJZ2 & Tubulin, alpha-8 & Tuba8 & 34.52 & 2 & 11 \\
\hline P68372 & Tubulin, beta-4B & Tubb4b & 61.12 & 3 & 18 \\
\hline P99024 & Tubulin, beta- 5 & Tubb5 & 61.26 & 4 & 18 \\
\hline Q922F4 & Tubulin, beta- 6 & Tubb6 & 25.95 & 2 & 9 \\
\hline
\end{tabular}

chains (Table 3). Various members of the proteoglycan network were identified as belonging to the families of small leucine-rich repeat proteins and proline-arginine-rich and leucine-rich repeat proteins. In addition, the regulatory proteins dermatopontin, nidogen and periostin, as well as the transmembrane receptor integrin and its coupling proteins fibronectin and vitronectin were identified to be present in the assessable diaphragm proteome.

\section{Proteomic map of the excitation-contraction coupling apparatus}

The main regulatory proteins involved in excitation-contraction coupling were identified in the assessable mouse diaphragm proteome, including the main muscle isoform RyR 1 of the ryanodine receptor $\mathrm{Ca}^{2+}$-release channel of the triad junction, and the $\alpha-1 \mathrm{~S}, \alpha-2 / \delta-1$ and $\beta-1$ subunits of the voltage-dependent L-type calcium channel of the transverse tubules (Table 4). The mass spectrometric survey also revealed the presence of the crucial $\mathrm{Ca}^{2+}$-binding proteins calsequestrin, sarcalumenin, regucalcin, and calmodulin, as well as the $\mathrm{Ca}^{2+}$ /calmodulin-dependent protein kinase and structural triad components such as triadin and junctophilins. Ion-pumping ATPases involved in the regulation of skeletal muscle relaxation and ion movements through the sarcolemma, as well as the propagation of action potential and the continuous maintenance and restoration of the resting membrane potential were also identified in diaphragm extracts.

\section{Comparative proteomic and bioinformatic analysis of the dystrophic $m d x-4 c v$ diaphragm}

Following the establishment of the assessable diaphragm proteome, we carried out a comparative proteomic analysis of the dystrophic $m d x-4 c v$ mouse model of dystrophinopathy that is characterized by the almost complete absence of the membrane cytoskeletal protein dystrophin. Characteristic histopathological changes in the dystrophic diaphragm, such as a higher frequency of central nuclei, an increased number 
Table 3 Proteomic map of the basal lamina and extracellular matrix from diaphragm muscle

\begin{tabular}{|c|c|c|c|c|c|}
\hline Accession & Protein name & Gene name & Coverage $\%$ & $\begin{array}{l}\text { Unique } \\
\text { Peptides }\end{array}$ & Peptides \\
\hline Q3V3R4 & Integrin, alpha-1 & Itga1 & 5.00 & 5 & 5 \\
\hline Q61739 & Integrin, alpha-6 & Itga6 & 2.52 & 2 & 2 \\
\hline Q61738 & Integrin, alpha-7 & Itga7 & 10.93 & 9 & 9 \\
\hline P09055 & Integrin, beta-1 & Itgb1 & 10.03 & 6 & 6 \\
\hline Q60675 & Laminin, alpha-2 & Lama2 & 23.41 & 56 & 56 \\
\hline P97927 & Laminin, alpha-4 & Lama4 & 11.95 & 15 & 15 \\
\hline Q61001 & Laminin, alpha-5 & Lama5 & 2.77 & 8 & 8 \\
\hline P02469 & Laminin, beta-1 & Lamb1 & 13.49 & 22 & 22 \\
\hline Q61292 & Laminin, beta- 2 & Lamb2 & 17.12 & 24 & 24 \\
\hline P02468 & Laminin subunit gamma-1 & Lamc1 & 20.66 & 27 & 27 \\
\hline Q05793 & $\begin{array}{l}\text { Basement membrane-specific heparan } \\
\text { sulfate proteoglycan core protein }\end{array}$ & Hspg2 & 17.51 & 42 & 42 \\
\hline P11087 & Collagen alpha-1(I) & Col1a1 & 6.74 & 7 & 7 \\
\hline Q01149 & Collagen alpha-2(I) & Col1a2 & 14.14 & 14 & 14 \\
\hline P08121 & Collagen alpha-1(III) & Col3a1 & 3.01 & 3 & 3 \\
\hline P08122 & Collagen alpha-2(IV) & Col4a2 & 2.05 & 3 & 3 \\
\hline Q3U962 & Collagen alpha-2(V) & Col5a2 & 1.94 & 2 & 2 \\
\hline Q04857 & Collagen alpha-1(VI) & Col6a1 & 28.00 & 20 & 20 \\
\hline Q02788 & Collagen alpha-2(VI) & Col6a2 & 23.69 & 21 & 21 \\
\hline A6H584 & Collagen alpha-5(VI) & Col6a5 & 15.76 & 26 & 30 \\
\hline Q8C6K9 & Collagen alpha-6(VI) & Col6a6 & 21.63 & 28 & 32 \\
\hline Q60847 & Collagen alpha-1(XII) & Col12a1 & 24.70 & 51 & 51 \\
\hline $\mathrm{Q} 80 \times 19$ & Collagen alpha-1(XIV) & Col14a1 & 1.80 & 2 & 2 \\
\hline O35206 & Collagen alpha-1(XV) & Col15a1 & 10.75 & 9 & 9 \\
\hline P10493 & Nidogen-1 & Nid1 & 24.90 & 20 & 21 \\
\hline O88322 & Nidogen-2 & Nid2 & 7.48 & 7 & 8 \\
\hline Q62000 & Mimecan & Ogn & 28.52 & 7 & 7 \\
\hline P28654 & Decorin & Den & 30.79 & 9 & 10 \\
\hline Q9JK53 & Prolargin & Prelp & 34.13 & 12 & 12 \\
\hline P50608 & Fibromodulin & Fmod & 22.87 & 8 & 8 \\
\hline Q9QZZ6 & Dermatopontin & Dpt & 9.45 & 2 & 2 \\
\hline P29788 & Vitronectin & Vtn & 6.28 & 2 & 2 \\
\hline P11276 & Fibronectin & Fn1 & 17.04 & 23 & 23 \\
\hline Q62009 & Periostin & Postn & 15.07 & 8 & 8 \\
\hline P28653 & Biglycan & Bgn & 32.25 & 9 & 10 \\
\hline P51885 & Lumican & Lum & 29.88 & 8 & 8 \\
\hline Q99MQ4 & Asporin & Aspn & 31.64 & 9 & 9 \\
\hline
\end{tabular}

of rounded fibres with differing diameter, fibre degeneration and inflammation, as well as the drastic reduction in the sarcolemmal expression of full-length dystrophin isoform Dp427-M, were confirmed by haematoxylin/eosin staining (Fig. 3a, d) and immunofluorescence microscopy of transverse cryo-sections (Fig. 3b, e). The systematic mass spectrometric survey of the Dp427-deficient diaphragm muscle revealed 289 decreased and 468 increased protein species. The top 40 proteomic hits of decreased versus increased proteins are listed in Tables 5 and 6, respectively. The remaining proteins with a changed abundance in muscular dystrophy are listed in the supplementary material as
Table S1 and Table S2. A heatmap for the 516 differentially abundant proteins with greater than/equal to twofold change is shown in Fig. 4. The drastic reduction in dystrophin isoform Dp427-M confirmed the mutant status of the $m d x-4 c v$ diaphragm used in this study, and the concomitant change in dystrophin-associated proteins was also verified for $\alpha 1$-syntrophin, $\alpha$-sarcoglycan, $\beta$-sarcoglycan, $\delta$-sarcoglycan and dystroglycan.

Interesting marker proteins with a drastically decreased concentration due to dystrophin deficiency were identified as enzymes and metabolite transporters of oxidative metabolism such as NADH dehydrogenase, fatty acid binding 
Table 4 Proteomic map of the excitation-contraction coupling and ion-handling apparatus from diaphragm muscle

\begin{tabular}{|c|c|c|c|c|c|}
\hline Accession & Protein name & Gene name & Coverage $\%$ & $\begin{array}{l}\text { Unique } \\
\text { Peptides }\end{array}$ & Peptides \\
\hline E9PZQ0 & Ryanodine receptor 1 & Ryr1 & 34.40 & 125 & 125 \\
\hline Q02789 & Voltage-dependent L-type calcium channel, alpha-1S & Cacna1s & 8.92 & 14 & 14 \\
\hline O08532 & Voltage-dependent calcium channel, alpha-2/delta- 1 & Cacna2d1 & 28.14 & 25 & 25 \\
\hline Q8R3Z5 & Voltage-dependent L-type calcium channel subunit beta- 1 & Cacnb1 & 25.70 & 13 & 13 \\
\hline O09165 & Calsequestrin-1 & Casq1 & 52.10 & 15 & 15 \\
\hline O09161 & Calsequestrin-2 & Casq2 & 34.70 & 10 & 10 \\
\hline Q7TQ48 & Sarcalumenin & Srl & 43.85 & 29 & 29 \\
\hline Q64374 & Regucalcin & $\operatorname{Rgn}$ & 27.09 & 7 & 7 \\
\hline P0DP28 & Calmodulin-3 & Calm3 & 62.42 & 9 & 10 \\
\hline P11798 & Calcium/calmodulin-dependent protein kinase type II, alpha & Camk2a & 12.34 & 2 & 4 \\
\hline P28652 & Calcium/calmodulin-dependent protein kinase type II, beta & Camk2b & 18.82 & 4 & 7 \\
\hline Q6PHZ2 & Calcium/calmodulin-dependent protein kinase type II, delta & Camk2d & 14.44 & 2 & 5 \\
\hline Q923T9 & Calcium/calmodulin-dependent protein kinase type II, gamma & Camk2g & 12.53 & 2 & 5 \\
\hline P56565 & Protein S100-A1 & S100a1 & 29.79 & 2 & 2 \\
\hline P08207 & Protein S100-A10 & S100a10 & 27.84 & 2 & 2 \\
\hline E9Q9K5 & Triadin & Triadin & 16.74 & 12 & 12 \\
\hline Q9ET80 & Junctophilin-1 & Jph1 & 23.18 & 11 & 11 \\
\hline Q9ET78 & Junctophilin-2 & Jph2 & 20.83 & 12 & 12 \\
\hline Q3MI48 & Junctional sarcoplasmic reticulum protein 1 & Jsrp1 & 35.24 & 7 & 7 \\
\hline Q8BZ71 & SH3 and cysteine-rich domain-containing protein STAC3 & Stac3 & 22.50 & 6 & 6 \\
\hline P70302 & Stromal interaction molecule 1 & Stim1 & 15.91 & 8 & 8 \\
\hline Q8R429 & Calcium ATPase SERCA1 & Atp2a1 & 47.89 & 35 & 51 \\
\hline O55143-2 & Calcium ATPase SERCA2 & Atp2a2 & 41.08 & 24 & 40 \\
\hline G5E829 & Plasma membrane calcium-transporting ATPase 1 & Atp2b1 & 4.34 & 3 & 4 \\
\hline Q6Q477-2 & Plasma membrane calcium-transporting ATPase 4 & Atp2b4 & 2.98 & 1 & 2 \\
\hline Q9ER60 & Sodium channel type 4 , alpha & $\operatorname{Scn} 4 \mathrm{a}$ & 1.63 & 2 & 2 \\
\hline Q8VDN2 & Sodium/potassium-ATPase, alpha-1 & Atp1a1 & 33.04 & 18 & 30 \\
\hline Q6PIE5 & Sodium/potassium-ATPase, alpha-2 & Atp1a2 & 41.57 & 26 & 38 \\
\hline P14094 & Sodium/potassium-ATPase, beta-1 & Atp1b1 & 28.95 & 6 & 6 \\
\hline
\end{tabular}

protein FABP3 and the oxygen-transporter myoglobin, the glycolytic enzymes phosphofructokinase, the $\mathrm{Ca}^{2+}$-binding protein parvalbumin, isoforms PLIN3 and PLIN5 of the lipid droplet-associated protein perilipin, the Z-disk protein myozenin-2, carbonic anhydrase CA3 and adenylate kinase AK1, as well as a broad spectrum of metabolic enzymes, structural components and signalling proteins (Table 5, Table S1). The decreased concentration of carbonic anhydrase CA3 was confirmed by comparative immunofluorescence microscopy (Fig. 3c, f).

An intriguing finding is the apparent switch of phosphoglycerate mutase isoforms between isozyme PGAM2 and isozyme PGMA1. The two isoforms of this key glycolytic enzyme mediate the interconversion of 3-phosphoglycerate and 2-phosphoglycerate. X-linked muscular dystrophy appears to be associated with a drastic reduction in the muscle-specific PGAM-M form and concomitant increase in the ubiquitous form of this enzyme (Tables 5, 6). The large number of increased diaphragm proteins included a variety of potential marker candidates of dystrophic changes, including cytochrome $\mathrm{P} 450$ isoforms $2 \mathrm{C} 70$ and 3A13, myosin-3 and the perinatal isoform of myosin heavy chain (myosin-8), the intermediate filament protein nestin, the extracellular matrix components vitronectin and tenascin, and the matricellular protein periostin (Table 6, Table S2).

Bioinformatics using publically available database searches was employed to analyse the clustering of changes in relation to protein classes and potential alterations in interaction patterns of diaphragm proteins involved in energy metabolism, the contractile apparatus, proteostasis and the extracellular matrix. The comparative PANTHER analysis (http://ww.pantherdb.org) presented in supplementary Figure S1 illustrates considerable concentration changes in diaphragm proteins belonging to the class of cytoskeletal components, transferases, oxidoreductases, hydrolases and enzyme modulators. There is a striking increase in nucleic 

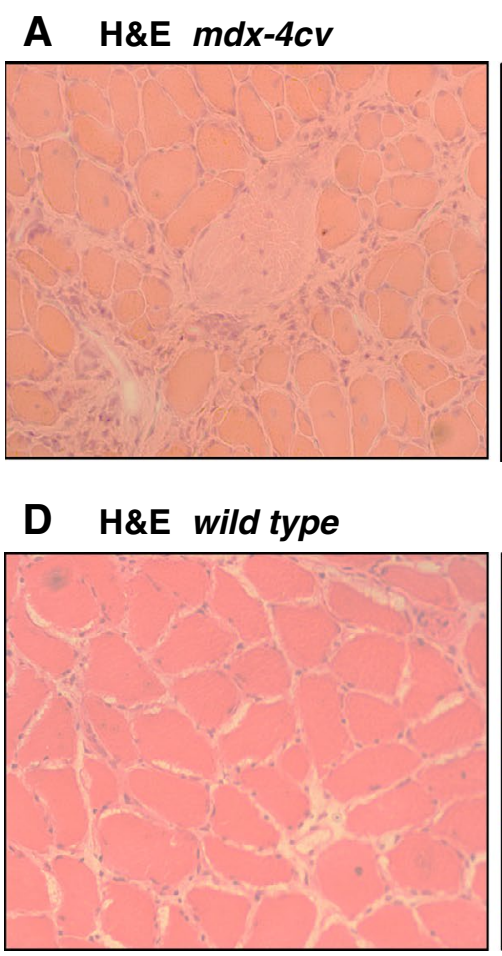

\section{B Dp427 $m d x-4 c v$}

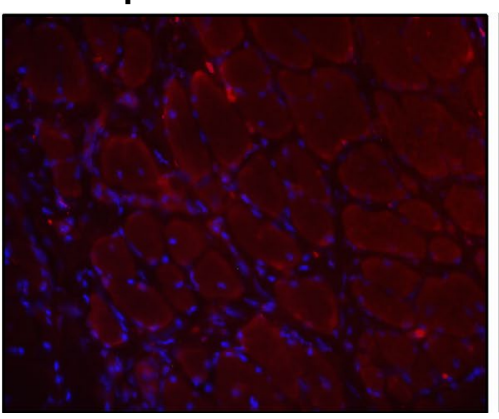

E Dp427 wild type

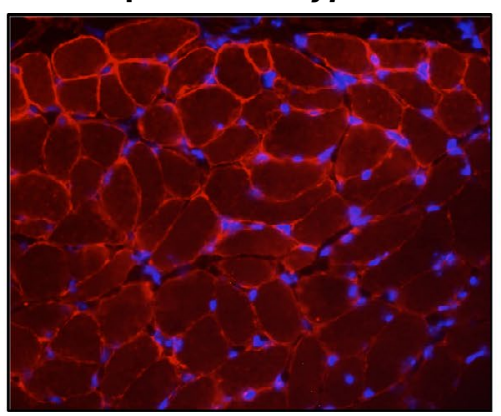

\section{CA3 $m d x-4 c v$}

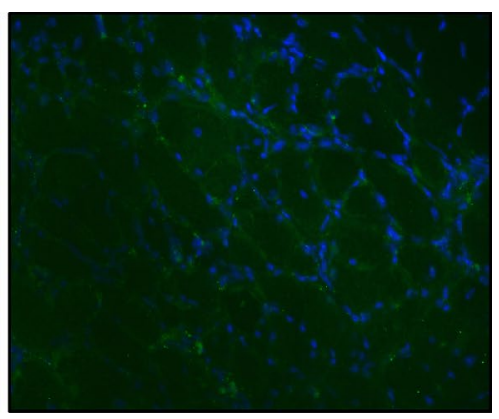

F CA3 wild type

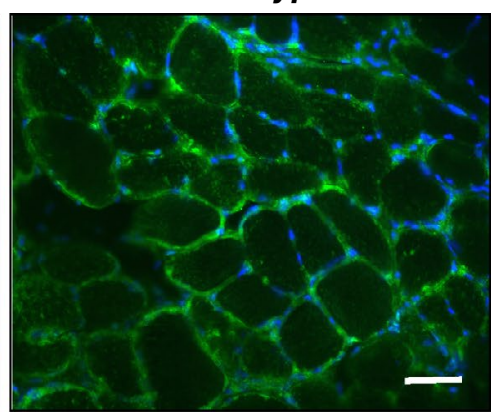

Fig. 3 Histological and immunofluorescence microscopical characterization of the dystrophic $m d x-4 c v$ diaphragm muscle. Shown are transverse tissue sections of 12-month dystrophic $m d x-4 c v$ (a-c) versus wild type (d-f) diaphragm specimens, stained with haematoxy-

acid binding proteins due to deficiency in dystrophin. An overview of reduced versus increased protein classes in relation to cellular component, molecular function and biological process in the dystrophic $m d x-4 c v$ mouse diaphragm is diagrammatically presented in Figs. 5 and 6, respectively. Shown are the most enriched GO terms for changed diaphragm proteins.

Dystrophinopathy-associated changes in functional protein association networks were determined by STRING analysis (https://string-db.org) and confirmed significant decreases in the dystrophin-glycoprotein complex and protein hubs involved in mitochondrial metabolism and fatty acid utilization, as well as glucose metabolism (Fig. 7). The abundance of a large number of subunits of the mitochondrial NADH dehydrogenase complex were shown to be reduced in dystrophic diaphragm. These effects on the expression levels of the NADH dehydrogenase, as well as succinate dehydrogenase, cytochrome-c reductase and ATP synthase, are illustrated in Figure S2. This supplementary figure shows the KEGG search and colour pathway analysis (Kyoto Encyclopedia of Genes and Genomes; https:// www.genome.jp/kegg) of the dystrophic $m d x-4 c v$ diaphragm focusing on oxidative phosphorylation, and is based on a dataset of 289 decreased proteins of which 28 protein species were found in the oxidative phosphorylation pathway. lin/eosin (a, d) or labelled with antibodies to the dystrophin isoform Dp427 (b, e) and the CA3 isoform of carbonic anhydrase (c, f). Magnification bar equals $50 \mu \mathrm{m}$

Proteins that are associated with the contractile apparatus were shown to undergo considerable changes in abundance, isoform expression levels and interaction patterns. The comparative STRING analysis of decreased versus increased contractile proteins revealed changes especially in myosin heavy chains, troponins and tropomyosin (Figs. 7, 8). Protein hubs with increased proteins were found to be linked to RNA processing, ribosomes, the proteasome, the cytochrome P450 complex and the Golgi apparatus. In agreement with elevated cellular stress levels and reactive myofibrosis in the dystrophin-deficient diaphragm, the findings from the STRING analysis presented in Fig. 8 indicates an apparent up-regulation of extracellular matrix proteins and molecular chaperones.

\section{Discussion}

As the main skeletal muscle involved in respiration, the proper functioning and physiological adaptation of the thoracic diaphragm is crucial for whole body homeostasis (Bordoni and Zanier 2013; Kocjan et al. 2017). In the past, histochemical, immunochemical and biochemical methods have been used to study the distribution and fibre type-specific expression patterns of muscle marker proteins 
Table 5 Mass spectrometric identification of proteins with a reduced abundance in the dystrophic $m d x-4 c v$ diaphragm

\begin{tabular}{|c|c|c|c|c|c|c|}
\hline Accession & Protein name & Gene name & $\begin{array}{l}\text { Unique } \\
\text { peptides }\end{array}$ & Confidence score & Anova (p) & Fold change \\
\hline Q8BK30 & $\begin{array}{l}\text { NADH dehydrogenase [ubiquinone] flavoprotein 3, mitochon- } \\
\text { drial }\end{array}$ & Ndufv3 & 2 & 7.8638 & $1.56 \mathrm{E}-04$ & -102.33 \\
\hline P70266 & 6-phosphofructo-2-kinase/fructose-2,6-bisphosphatase 1 & Pfkfb1 & 2 & 6.4705 & $8.94 \mathrm{E}-07$ & -14.07 \\
\hline P11404 & Fatty acid-binding protein, heart & Fabp3 & 3 & 13.5990 & $1.97 \mathrm{E}-08$ & -14.01 \\
\hline P32848 & Parvalbumin alpha & Pvalb & 4 & 12.1287 & $5.58 \mathrm{E}-10$ & -13.99 \\
\hline P11531 & Dystrophin Dp427-M & Dmd & 40 & 153.9807 & $5.19 \mathrm{E}-13$ & -12.50 \\
\hline Q9JLV1 & BAG family molecular chaperone regulator 3 & Bag3 & 2 & 7.4879 & $6.95 \mathrm{E}-08$ & -8.73 \\
\hline Q8BVZ1 & Perilipin-5 & Plin5 & 2 & 6.5124 & $7.47 \mathrm{E}-06$ & -8.66 \\
\hline P70236 & Dual specificity mitogen-activated protein kinase kinase 6 & Map2k6 & 2 & 7.5185 & $1.87 \mathrm{E}-08$ & -8.08 \\
\hline P28650 & Adenylosuccinate synthetase isozyme 1 & Adssl1 & 4 & 17.2037 & $1.51 \mathrm{E}-04$ & -7.95 \\
\hline Q8VCF0 & Mitochondrial antiviral-signaling protein & Mavs & 3 & 12.5693 & $1.24 \mathrm{E}-07$ & -7.87 \\
\hline O70250 & Phosphoglycerate mutase 2 & Pgam2 & 2 & 8.0247 & $7.10 \mathrm{E}-07$ & -7.45 \\
\hline Q9DBG5 & Perilipin-3 & Plin3 & 4 & 15.7082 & $1.31 \mathrm{E}-08$ & -7.44 \\
\hline Q61234 & Alpha-1-syntrophin & Snta1 & 4 & 11.9300 & $3.02 \mathrm{E}-09$ & -6.87 \\
\hline O88492 & Perilipin-4 & Plin4 & 9 & 28.2648 & $1.31 \mathrm{E}-09$ & -6.84 \\
\hline P04247 & Myoglobin & $\mathrm{Mb}$ & 7 & 31.6075 & $1.81 \mathrm{E}-05$ & -6.56 \\
\hline A3KG59 & Peptidase M20 domain-containing protein 2 & $\operatorname{Pm} 20 \mathrm{~d} 2$ & 2 & 7.0814 & $1.14 \mathrm{E}-05$ & -6.54 \\
\hline P82350 & Alpha-sarcoglycan & Sgca & 3 & 9.9284 & $6.08 \mathrm{E}-06$ & -6.21 \\
\hline Q149B8 & PGC-1 and ERR-induced regulator in muscle protein 1 & Perm1 & 3 & 10.2636 & $2.36 \mathrm{E}-05$ & -6.18 \\
\hline Q9JJW5 & Myozenin-2 & Myoz2 & 4 & 14.02387 & $2.29 \mathrm{E}-05$ & -6.10 \\
\hline Q9ET78 & Junctophilin-2 & Jph2 & 2 & 5.0768 & $2.26 \mathrm{E}-02$ & -5.89 \\
\hline Q8K1Z0 & Ubiquinone biosynthesis protein $\mathrm{COQ} 9$, mitochondrial & Coq9 & 2 & 8.1729 & $6.61 \mathrm{E}-05$ & -5.85 \\
\hline Q8BH86 & D-glutamate cyclase, mitochondrial & $1 \mathrm{SV}$ & 2 & 11.7460 & $3.31 \mathrm{E}-05$ & -5.07 \\
\hline Q9R0Y5 & Adenylate kinase isoenzyme 1 & Ak1 & 3 & 16.4163 & $1.32 \mathrm{E}-05$ & -4.78 \\
\hline Q9ET80 & Junctophilin-1 & Jph1 & 2 & 6.1080 & $3.79 \mathrm{E}-04$ & -4.76 \\
\hline Q9D172 & ES1 protein homolog, mitochondrial & D10Jhu81e & 4 & 10.9255 & $1.44 \mathrm{E}-06$ & -4.61 \\
\hline Q99MR9 & Protein phosphatase 1 regulatory subunit $3 \mathrm{~A}$ & Ppp1r3a & 4 & 18.3577 & $1.23 \mathrm{E}-04$ & -4.55 \\
\hline E9QA62 & Leiomodin-3 & Lmod3 & 3 & 9.2948 & $1.28 \mathrm{E}-07$ & -4.38 \\
\hline Q5SX39 & Myosin-4 & Myh4 & 15 & 69.7577 & $4.62 \mathrm{E}-06$ & -4.26 \\
\hline Q9WUR9 & Adenylate kinase 4 , mitochondrial & Ak4 & 3 & 9.3956 & $7.30 \mathrm{E}-05$ & -4.25 \\
\hline Q99NB1 & Acetyl-coenzyme A synthetase 2-like, mitochondrial & Acss 1 & 3 & 13.5025 & $1.07 \mathrm{E}-04$ & -4.23 \\
\hline P07310 & Creatine kinase M-type & $\mathrm{Ckm}$ & 11 & 53.1162 & $2.97 \mathrm{E}-07$ & -4.22 \\
\hline Q811I0 & ATP synthase mitochondrial F1 complex assembly factor 1 & Atpaf1 & 2 & 6.9054 & $4.60 \mathrm{E}-05$ & -4.22 \\
\hline Q9DC69 & $\begin{array}{l}\text { NADH dehydrogenase [ubiquinone] } 1 \text { alpha subcomplex subu- } \\
\text { nit 9, mitochondrial }\end{array}$ & Ndufa9 & 2 & 5.8310 & $3.53 \mathrm{E}-08$ & -4.10 \\
\hline Q99LM3 & Smoothelin-like protein 1 & Smtnl1 & 2 & 8.2936 & $3.77 \mathrm{E}-05$ & -4.08 \\
\hline Q8VCR8 & Myosin light chain kinase 2, skeletal/cardiac muscle & Mylk2 & 2 & 6.7668 & $1.39 \mathrm{E}-06$ & -4.02 \\
\hline $\mathrm{P} 23506-2$ & $\begin{array}{l}\text { Isoform } 2 \text { of Protein-L-isoaspartate(D-aspartate) O-methyl- } \\
\text { transferase }\end{array}$ & Pcmt1 & 2 & 6.9031 & $1.28 \mathrm{E}-04$ & -3.92 \\
\hline Q8CC35 & Synaptopodin & Synpo & 2 & 5.3858 & $2.72 \mathrm{E}-07$ & -3.89 \\
\hline P12367 & $\begin{array}{l}\text { cAMP-dependent protein kinase type II-alpha regulatory } \\
\text { subunit }\end{array}$ & Prkar2a & 2 & 7.6514 & $2.30 \mathrm{E}-02$ & -3.89 \\
\hline P16015 & Carbonic anhydrase 3 & $\mathrm{Ca} 3$ & 2 & 12.7933 & $7.36 \mathrm{E}-04$ & -3.86 \\
\hline Q9DCW4 & Electron transfer flavoprotein subunit beta & Etfb & 4 & 13.6339 & $2.12 \mathrm{E}-06$ & -3.76 \\
\hline
\end{tabular}

Listed are the top 40 proteomic hits with significant concentration changes in dystrophin-deficient muscle tissue, established with the help of an Orbitrap Fusion Tribrid mass spectrometer. In addition, mass spectrometrically identified diaphragm proteins in the positions 41-289 are listed in Supplementary Table S1 
Table 6 Mass spectrometric identification of proteins with an increased abundance in the dystrophic $m d x-4 c v$ diaphragm

\begin{tabular}{|c|c|c|c|c|c|c|}
\hline Accession & Protein name & Gene name & $\begin{array}{l}\text { Unique } \\
\text { peptides }\end{array}$ & Confidence score & Anova (p) & Fold change \\
\hline Q91W64 & Cytochrome P450 2C70 & Сyp2c70 & 2 & 5.2815 & $2.20 \mathrm{E}-02$ & Infinity \\
\hline O35423 & Serine-pyruvate aminotransferase, mitochondrial & Agxt & 2 & 5.13381 & $4.36 \mathrm{E}-03$ & 224.53 \\
\hline Q9DBJ1 & Phosphoglycerate mutase 1 & Pgam1 & 2 & 10.2674 & $2.21 \mathrm{E}-03$ & 195.52 \\
\hline Q8BU30 & Isoleucine-tRNA ligase, cytoplasmic & Iars & 2 & 4.6829 & $3.67 \mathrm{E}-04$ & 70.96 \\
\hline P13542 & Myosin-8 & Myh8 & 10 & 41.2730 & $1.95 \mathrm{E}-11$ & 57.09 \\
\hline Q920E5 & Farnesyl pyrophosphate synthase & Fdps & 3 & 10.3610 & $5.81 \mathrm{E}-03$ & 44.57 \\
\hline Q640N1 & Adipocyte enhancer-binding protein 1 & Aebp1 & 4 & 13.0625 & $4.81 \mathrm{E}-08$ & 44.23 \\
\hline Q64464 & Cytochrome P450 3A13 & Cyp3a13 & 2 & 5.7456 & $2.40 \mathrm{E}-02$ & 43.98 \\
\hline P29788 & Vitronectin & Vtn & 2 & 8.2586 & $9.52 \mathrm{E}-07$ & 41.9 \\
\hline Q922D8 & C-1-tetrahydrofolate synthase, cytoplasmic & Mthfd1 & 2 & 7.8328 & $2.29 \mathrm{E}-02$ & 38.15 \\
\hline Q920A5 & Retinoid-inducible serine carboxypeptidase & Scpep1 & 2 & 4.8029 & $3.30 \mathrm{E}-03$ & 37.77 \\
\hline Q9CW42 & Mitochondrial amidoxime-reducing component 1 & Marc1 & 2 & 4.9948 & $2.04 \mathrm{E}-03$ & 33.6 \\
\hline Q9DD20 & Methyltransferase-like protein 7B & Mettl7b & 2 & 5.7890 & $2.03 \mathrm{E}-05$ & 27.17 \\
\hline $\mathrm{O} 35841$ & Apoptosis inhibitor 5 & Api5 & 2 & 8.7338 & $1.14 \mathrm{E}-04$ & 23.45 \\
\hline Q6P5H2 & Nestin & Nes & 3 & 10.1586 & $1.91 \mathrm{E}-09$ & 23.44 \\
\hline Q91×91 & Nicotinate-nucleotide pyrophosphorylase [carboxylating] & Qprt & 2 & 4.6746 & $2.42 \mathrm{E}-02$ & 22.58 \\
\hline Q80YX1 & Tenascin & Tnc & 2 & 7.0335 & $7.48 \mathrm{E}-08$ & 21.63 \\
\hline P05784 & Keratin, type I cytoskeletal 18 & Krt18 & 3 & 10.7953 & $5.88 \mathrm{E}-03$ & 17.86 \\
\hline Q64674 & Spermidine synthase & Srm & 2 & 7.07431 & $7.38 \mathrm{E}-03$ & 17.58 \\
\hline Q8BH97 & Reticulocalbin-3 & Ren3 & 4 & 11.3589 & $3.83 \mathrm{E}-07$ & 17.55 \\
\hline Q9DBF1 & Alpha-aminoadipic semialdehyde dehydrogenase & Aldh7a1 & 2 & 7.1164 & $1.58 \mathrm{E}-02$ & 16.1 \\
\hline P16110 & Galectin-3 & Lgals3 & 2 & 8.9432 & $8.12 \mathrm{E}-09$ & 16.08 \\
\hline Q91YI0 & Argininosuccinate lyase & Asl & 2 & 5.1020 & $1.77 \mathrm{E}-03$ & 15.53 \\
\hline Q62009 & Periostin & Postn & 8 & 27.5746 & $1.11 \mathrm{E}-11$ & 15.26 \\
\hline Q9QZD8 & Mitochondrial dicarboxylate carrier & Slc25a10 & 2 & 4.1041 & $7.83 \mathrm{E}-03$ & 14.95 \\
\hline Q64435 & UDP-glucuronosyltransferase $1-6$ & Ugt1a6 & 2 & 7.4589 & $8.84 \mathrm{E}-04$ & 14.58 \\
\hline Q91XD4 & Formimidoyltransferase-cyclodeaminase & Ftcd & 2 & 5.2185 & $1.22 \mathrm{E}-03$ & 13.29 \\
\hline $\mathrm{Q} 80 \times 19$ & Collagen alpha-1(XIV) chain & Col14a1 & 3 & 7.4739 & $1.65 \mathrm{E}-02$ & 13.25 \\
\hline P13541 & Myosin-3 & Myh3 & 19 & 80.7618 & $1.54 \mathrm{E}-10$ & 12.93 \\
\hline Q80UM7 & Mannosyl-oligosaccharide glucosidase & Mogs & 3 & 8.9233 & $5.99 \mathrm{E}-05$ & 12.9 \\
\hline Q9R0H0 & Peroxisomal acyl-coenzyme A oxidase 1 & Acox 1 & 3 & 10.7203 & $9.07 \mathrm{E}-03$ & 12.51 \\
\hline P97872 & Dimethylaniline monooxygenase [N-oxide-forming] 5 & Fmo5 & 4 & 10.5899 & $3.38 \mathrm{E}-02$ & 12.3 \\
\hline P09470 & Angiotensin-converting enzyme & Ace & 2 & 8.4918 & $2.82 \mathrm{E}-09$ & 11.9 \\
\hline Q8R164 & Valacyclovir hydrolase & Bphl & 2 & 7.2247 & $4.48 \mathrm{E}-03$ & 11.86 \\
\hline Q8CFX1 & GDH/6PGL endoplasmic bifunctional protein & H6pd & 2 & 6.7554 & $9.00 \mathrm{E}-04$ & 11.84 \\
\hline Q99PV0 & Pre-mRNA-processing-splicing factor 8 & Prpf8 & 4 & 12.9865 & $3.56 \mathrm{E}-04$ & 11.77 \\
\hline P97501 & Dimethylaniline monooxygenase [N-oxide-forming] 3 & Fmo3 & 2 & 4.9013 & $1.99 \mathrm{E}-03$ & 11.26 \\
\hline P09541 & Myosin light chain 4 & Myl4 & 3 & 9.7528 & $2.12 \mathrm{E}-05$ & 11.03 \\
\hline O08601 & Microsomal triglyceride transfer protein large subunit & Mttp & 3 & 9.6687 & $2.41 \mathrm{E}-02$ & 10.66 \\
\hline Q4U4S6 & Xin actin-binding repeat-containing protein 2 & Xirp2 & 7 & 23.4318 & $7.44 \mathrm{E}-09$ & 10.52 \\
\hline
\end{tabular}

Listed are the top 40 proteomic hits with significant concentration changes in dystrophin-deficient muscle tissue, established with the help of an Orbitrap Fusion Tribrid mass spectrometer. In addition, mass spectrometrically identified diaphragm proteins in the positions 41-468 are listed in supplementary Table S2

during development, maturation and aging of this specialized type of contractile tissue (Agbulut et al. 2003; Geiger et al. 2006; Greising et al. 2015). Building on these studies and to verify the presence of key muscle protein isoforms by mass spectrometry, this report outlines the findings from the systematic survey of total extracts from mouse diaphragm using an Orbitrap Fusion Tribrid mass spectrometer. The establishment of an initial reference map of the experimentally assessable diaphragm proteome revealed an interesting constellation of myosin heavy chains and associated 
Fig. 4 Label-free quantitative proteomic analysis of wild-type versus $m d x-4 c v$ diaphragm. Depicted is the result from hierarchical clustering of the mean protein expression values of 516 statistically significant differentially abundant proteins, performed using Perseus software. Hierarchical clustering of z-score normalised intensity values illustrates diagrammatically the alterations in protein abundance between wild-type and $m d x-4 c v$ diaphragm muscle
Fig. 5 Overview of reduced protein classes in relation to cellular component, molecular function and biological process in the dystrophic $m d x-4 c v$ mouse diaphragm. Shown are the most enriched GO terms for proteins with $>$ twofold decreased abundance. Fold enrichment values are relative to random expression. For the enrichment values the minimum number of genes for the corresponding term was set to 5, EASE threshold was set to p 0.05, and Benjamini scores 0.05 . Shown in light grey are the six most enriched cellular component GO terms, in dark grey are the six most enriched molecular function GO terms and in black are the six most enriched biological process GO terms

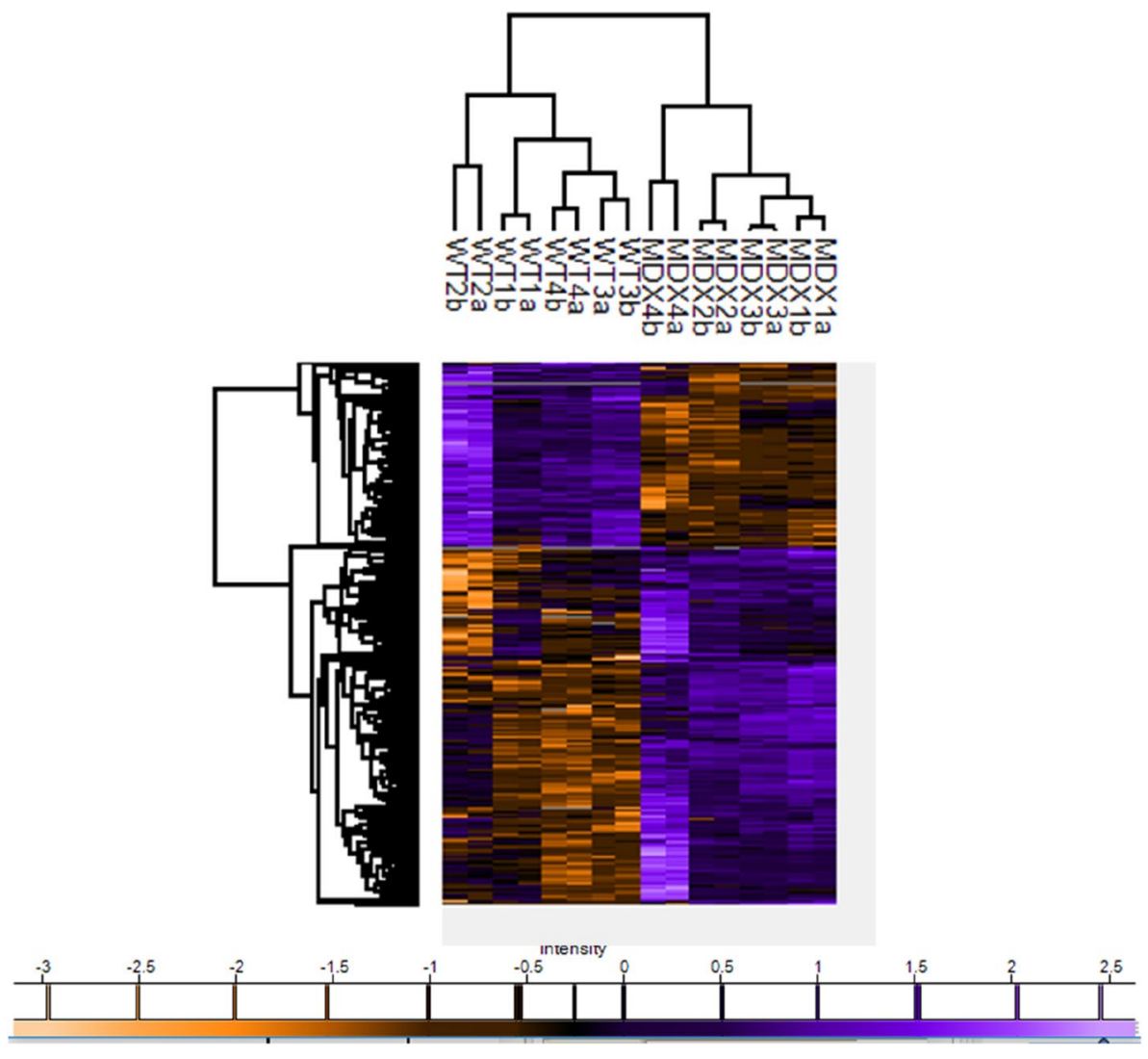

Proteome-wide decreases in the dystrophic $m d x-4 c v$ diaphragm

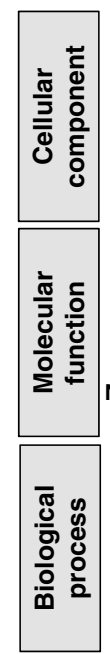

GO Term

Benjamini

Myofibril

Sarcoplasmic reticulum

Mitochondrial nucleoid

I band

Respiratory chain

Mitochondrial respiratory chain complex I

Catalytic activity

Fatty-acyl-CoA binding

NAD binding

Electron carrier activity

NADH dehydrogenase (ubiquinone) activity NADH dehydrogenase activity

Sarcomere organisation

Muscle contraction

Fatty acid beta-oxidation

Tricarboxylic acid cycle

Regulation of muscle contraction

Myofibril assembly

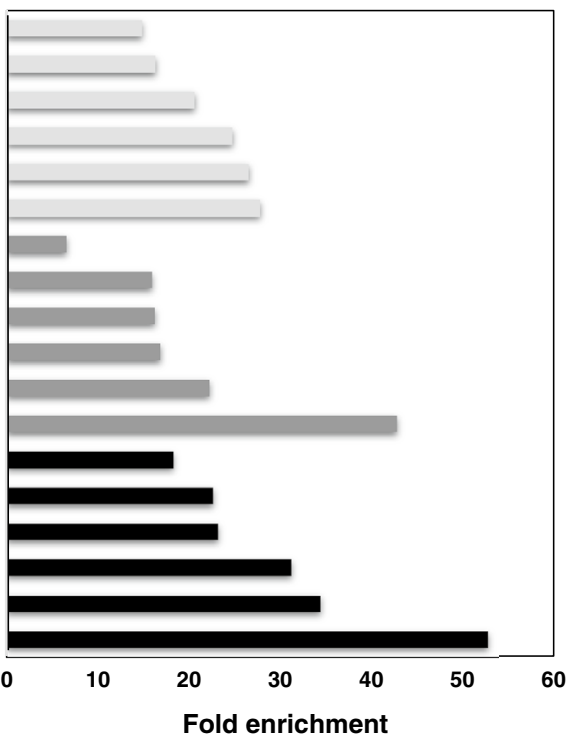

$4.6 \mathrm{E}-3$

9.4E-6

2.0E-6

$7.0 \mathrm{E}-4$

3.0E-12

$1.5 \mathrm{E}-10$

$5.9 \mathrm{E}-12$

$7.8 \mathrm{E}-3$

$3.8 \mathrm{E}-5$

$3.6 \mathrm{E}-5$

3.4E-5

2.0E-4

8.9E-3

1.1E-7

$5.8 \mathrm{E}-7$

$5.6 \mathrm{E}-7$

$3.8 \mathrm{E}-6$

$3.5 \mathrm{E}-7$ contractile proteins, as well as key components of the extrasarcomeric cytoskeleton. Another focus of this study was on the protein constituents of the excitation-contraction coupling apparatus and associated $\mathrm{Ca}^{2+}$-handling components, and the main structural elements of the extracellular matrix of skeletal muscle fibres.

The diaphragm contains a mixture of slow and fast fibres, which reflects the differential need of predominantly slow 


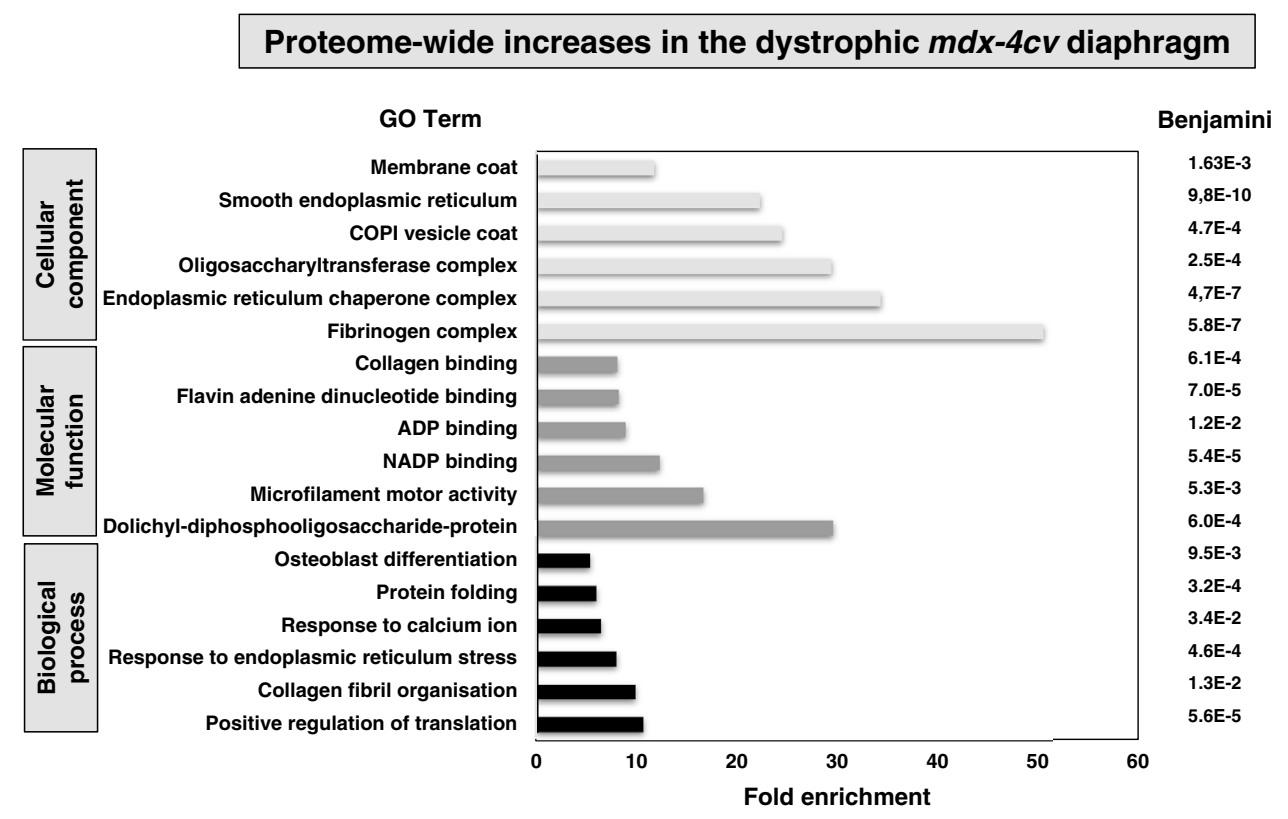

Fig. 6 Overview of increased protein classes in relation to cellular component, molecular function and biological process in the dystrophic $m d x-4 c v$ mouse diaphragm. Shown are the most enriched GO terms for proteins with $>$ twofold increased abundance. Fold enrichment values are relative to random expression. For the enrichment values the minimum number of genes for the corresponding term

fibre contraction during periods of moderate breathing versus the increased recruitment of fast fibres during elevated breathing (Polla et al. 2004). On the cellular and molecular level, the heterogeneous fibre type composition of normal diaphragm muscle and fibre changes during development, adaptation, disuse, hypoxia, disease or aging can be conveniently assessed by standardized histochemical or immunohistochemical staining procedures, as well as the biochemical measurement of myosin heavy chain isoform expression levels (Geiger et al. 2006; Greising et al. 2015; Hussain et al. 2016). In rodents, the proportion of fast fibres is higher in respiratory muscles as compared to humans, probably due to varying ventilation rates in differently sized mammalian organisms (Lieberman et al. 1973; Mizuno 1991). In 90 day old mice, myosin heavy chain isoforms were shown to exist as fast isoforms MyHC-IIA, MyHC-IIX/IID and MyHC-IIB, and the slow isoform MyHC-I/ $\beta$ (Agbulut et al. 2003). The proteomic profiling of normal diaphragm muscle corroborates the complexity of myosin expression levels of the thick filament and showed the presence of myosin heavy chains myosin-1 (MyHC-2x), myosin-3 (MyHC-3), myosin-4 (MyHC-2b), myosin-7 (MyHC-slow) and myosin-8 (MyHCperinatal), as well as the myosin light chains MLC1/MLC3, MLC2 (muscle), MLC2 (slow) and MLC3 (slow) (Holland and Ohlendieck 2013). The presence of the main $\alpha$-actin component of the thin filament and its associated regulatory troponin and tropomyosin complexes, and the listing was set to 5, EASE threshold was set to p 0.05 , and Benjamini scores 0.05 . Shown in light grey are the six most enriched cellular component GO terms, in dark grey are the six most enriched molecular function GO terms and in black are the six most enriched biological process $\mathrm{GO}$ terms

of auxiliary sarcomeric proteins such as $\alpha$-actinins, filamin, ankyrins, telethonin, myomesins and myozenins confirmed the bioanalytical sensitivity of the proteomic approach.

Notable mass spectrometric identifications are that of the extremely large proteins titin and obscurin by 1299 and 157 unique peptides, respectively. Titin is the largest mammalian protein with a molecular mass of approximately 3-4 MDa and spans half the sarcomere structure in muscle fibres (Krüger and Kötter 2016). Proteins of this size can usually not be analysed by routine two-dimensional gel electrophoresis, so this finding demonstrates the advantage of liquid chromatography as a protein separation technique for studying giant muscle protein species (Deshmukh et al. 2015). The bioanalytical challenges encountered during the systematic separation and identification of large muscle proteins using gel-based methods versus liquid chromatography during proteomic screening studies have been recently reviewed (Murphy et al. 2019a). Proteomic approaches with a focus on giant protein species and large protein complexes, such as protein assemblies within the sarcomere, the cytoskeleton and the sarcoplasmic reticulum, have mostly been studied using liquid chromatography, but can also be carried out by one-dimensional gel electrophoresis and the GeLC-MS method (Murphy and Ohlendieck 2018). The same technical issue is relevant for the routine proteomic analysis of a variety of extra-sarcomeric proteins, ion channels and extracellular matrix proteins. In this study, the full-length dystrophin 


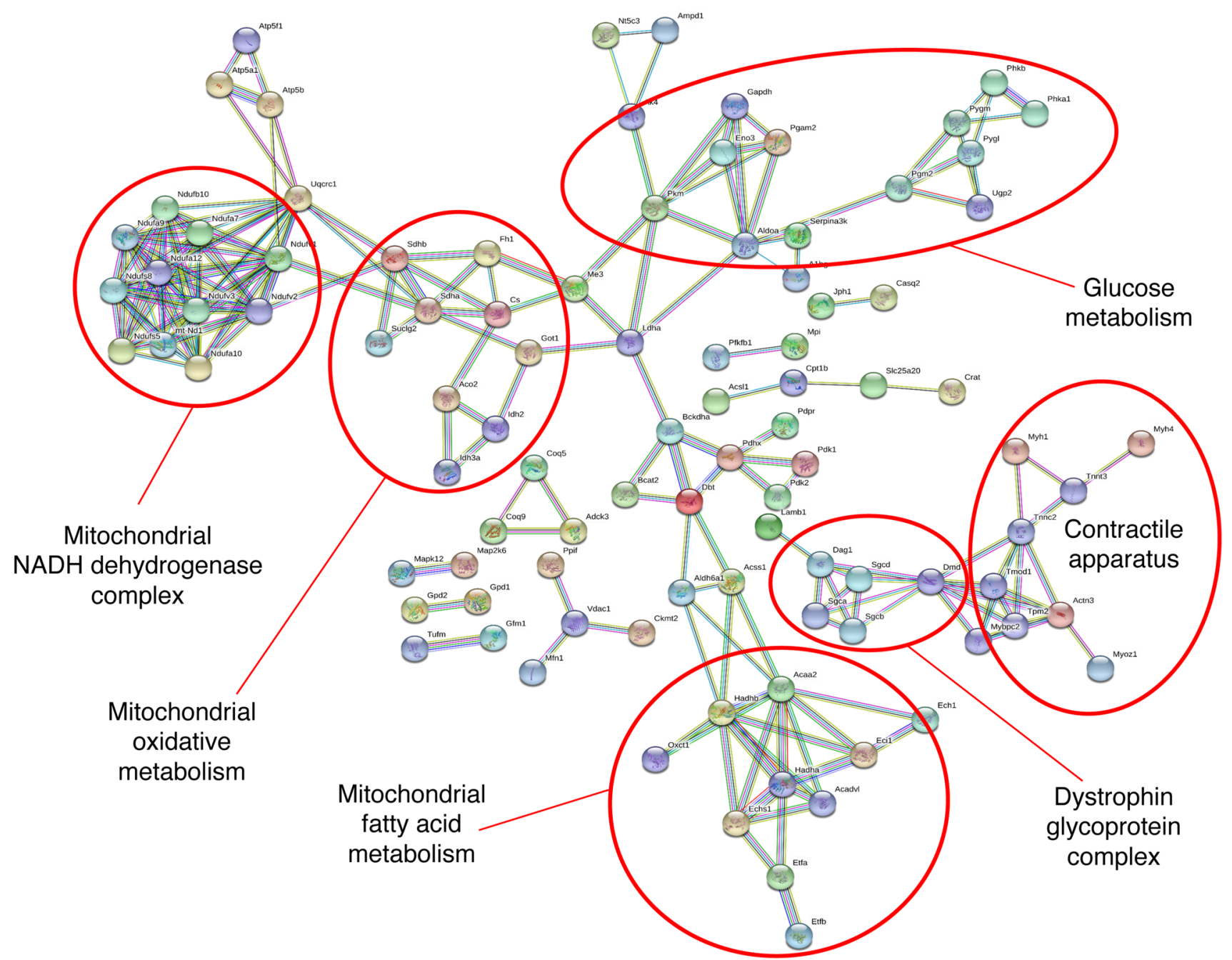

Fig. 7 Bioinformatics analysis of potential interaction patterns of decreased proteins in the dystrophic $m d x-4 c v$ mouse diaphragm. The bioinformatics software programme STRING was used to summarize interaction hubs by proteins with a decreased concentration in the $m d x-4 c v$ mouse diaphragm. The mutant status of the investigated

isoform $\mathrm{Dp} 427-\mathrm{M}$ and the large cytoskeletal protein plectin were detected by 90 and 213 unique peptides, respectively, which presents an excellent sequence coverage of these highmolecular-mass components. These results demonstrate that the LC-MS/MS approach using an Orbitrap Fusion Tribrid mass spectrometer is suitable for the detailed evaluation of the various components of the intracellular cytoskeletal network of contractile fibres, such as tubulins, actins, vinculin, desmin, vimentin and synemin (Henderson et al. 2017).

The sequence of large proteins of the basal lamina and the extracellular matrix, such as laminin, the basement membrane-specific heparan sulfate proteoglycan core protein, collagens and fibronectin was also well covered by the proteomic analysis of normal diaphragm muscle, which is a prerequisite for proper comparative studies of skeletal muscle muscle was confirmed by the drastic reduction in the dystrophinglycoprotein complex. Other protein clusters, such as the contractile apparatus, NADH dehydrogenase, and enzyme complexes involved in glucose and oxidative metabolism, are marked

fibrosis (Holland et al. 2016). The large ryanodine receptor $\mathrm{Ca}^{2+}$-release channel of the sarcoplasmic reticulum (Santulli et al. 2017) and key proteins of the highly complex network of $\mathrm{Ca}^{2+}$-regulatory proteins, such as the various subunits of the voltage-dependent $\mathrm{L}$-type $\mathrm{Ca}^{2+}$-channel, $\mathrm{Ca}^{2+}$-ATPases, luminal and cytosolic $\mathrm{Ca}^{2+}$-binding proteins, $\mathrm{Ca}^{2+}$-shuttle proteins and other ion-handling components were also identified, demonstrating the usefulness of this proteomic approach for the detailed analysis of potential changes in the excitation-contraction coupling apparatus during skeletal muscle adaptations or pathophysiological processes.

The progressive respiratory decline in many neuromuscular disorders of childhood (Buu 2017) warrants detailed studies into the molecular mechanisms of diaphragm abnormalities such as seen in Duchenne muscular dystrophy 


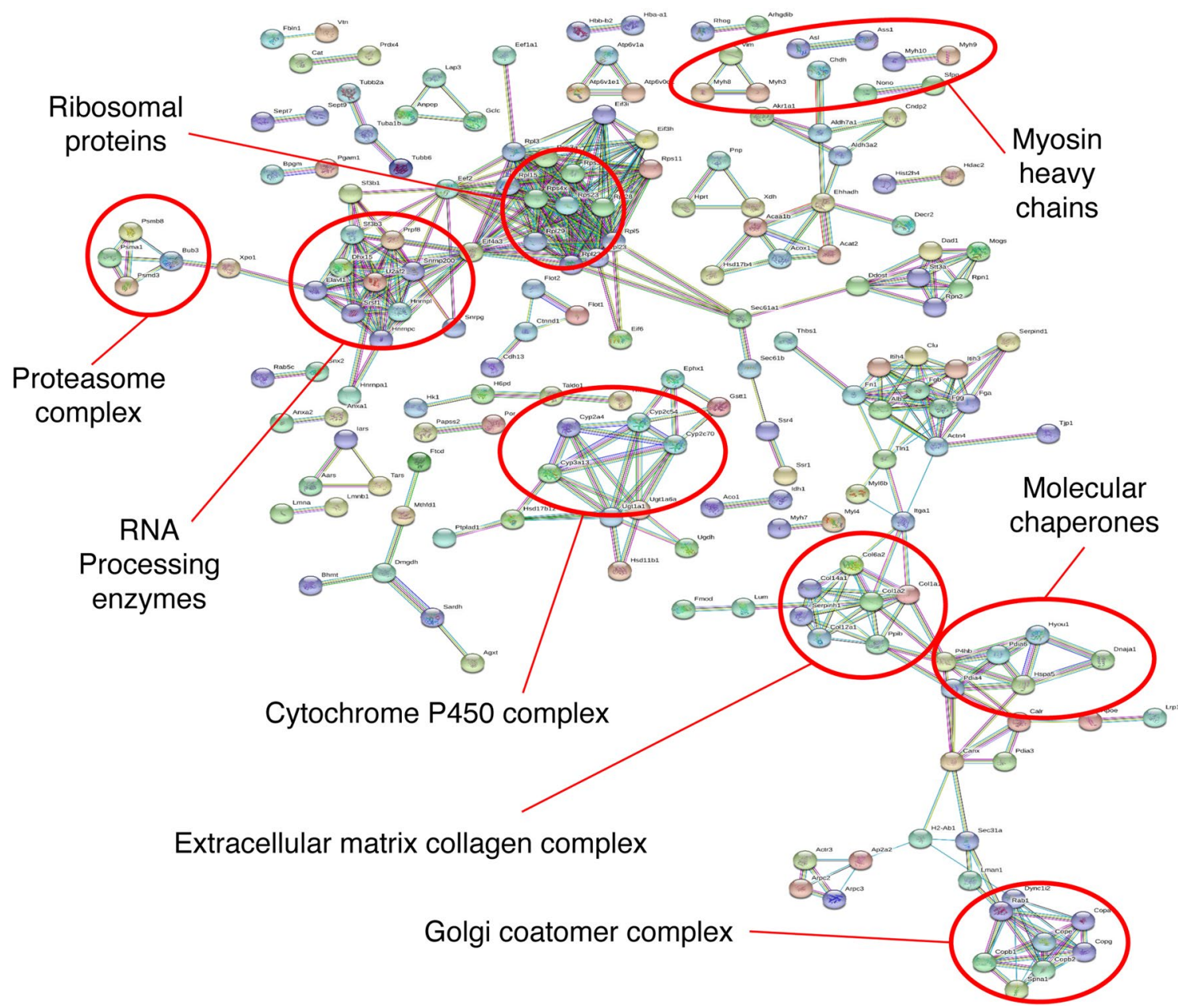

Fig. 8 Bioinformatics analysis of potential interaction patterns of increased proteins in the dystrophic $m d x-4 c v$ mouse diaphragm. The bioinformatics software programme STRING was used to summarize interaction hubs of proteins with an increased concentration in

(Khirani et al. 2014). Building on the initial establishment of the proteomic map of the normal diaphragm, this report outlines the suitability of comparative proteomic analyses for the unequivocal identification of proteome-wide changes due to deficiency in the membrane cytoskeletal protein dystrophin. The refined proteomic profiling of the $m d x-4 c v$ diaphragm using a highly sensitive mass spectrometer revealed a wider scope of considerable differential changes in the contractile apparatus, the extra-sarcomeric cytoskeleton, the extracellular matrix and excitation-contraction coupling proteins, as previously reported. In contrast to the already published proteomic maps of the dystrophic diaphragm (Doran et al. 2006, 2009; Carberry et al. 2012; Matsumura et al. 2013; Holland et al. 2015a, b), the new dataset of identified proteins with a changed concentration due to dystrophic and fibrotic changes is more comprehensive, and shows detailed alterations in a large number of pathways and protein hubs (Holland et al. 2013; Fuller et al. 2016). the $m d x-4 c v$ mouse diaphragm. Protein clusters involved in ribosomal function, the proteasome, the cytochrome P450 complex, the Golgi apparatus, the extracellular matrix, the contractile apparatus, and the cellular stress response are marked

Expression changes in MyHC isoforms in the dystrophic diaphragm were previously determined by gel electrophoretic analysis and immunofluorescence microscopy and indicated age-related differences in fibre type specification (Petrof et al. 1993; Coirault et al. 1999; Muller et al. 2001). The overall trend of isoform shifting agrees with the mass spectrometric findings presented in this report. The proteomic identification of increases in myosin-3 (MyHC-3), myosin-7 (MyHC-slow) and myosin-8, the perinatal isoform of myosin heavy chain, which is indicative of fibre regeneration processes, agrees with previous analyses of MyHC changes in the $m d x$ diaphragm (Petrof et al. 1993). The reported drastic decrease in the IIx/b fiber population during maturation of the $m d x$ diaphragm (Petrof et al. 1993; Coirault et al. 1999) was also confirmed by the new proteomic dataset on the 10-month old $m d x-4 c v$ diaphragm that showed a reduced concentration of myosin-4 (MyHC-2b) and myosin-1 (MyHC-2x), as well as myosin light chains 2 
and $1 / 3$ and myosin-binding protein MBP-C. The decrease in several isoforms of the M-band protein myomesin and Z-disk component myozenin, as well as the observed upregulation of the extra-sarcomeric cytoskeletal proteins vimentin and tubulins, is in agreement with previous proteomic studies (Holland et al. 2015a; Murphy et al. 2015a).

A central pathophysiological mechanism involved in progressive skeletal muscle degeneration is based on high levels of $\mathrm{Ca}^{2+}$-influx through sarcolemmal $\mathrm{Ca}^{2+}$-leak channels, which triggers elevated levels of $\mathrm{Ca}^{2+}$-dependent proteolysis in dystrophin-deficient fibres (Hopf et al. 2007) and impaired $\mathrm{Ca}^{2+}$-buffering in the lumen of the sarcoplasmic reticulum (Culligan et al. 2002). Stretch-activated $\mathrm{Ca}^{2+}$-channels are believed to play a central role in the generation of the dystrophic phenotype (Matsumura et al. 2011). High cytosolic $\mathrm{Ca}^{2+}$-levels have a modifying effect on the rate of $\mathrm{Ca}^{2+}$-release and -reuptake (DeLuca et al. 1998) and thereby change the excitation-contraction coupling mechanism in dystrophic fibres (Mázala et al. 2015). The idea of impaired coupling between sarcolemmal excitation, $\mathrm{Ca}^{2+}$-release from the sarcoplasmic reticulum, physiological coupling to fibre contraction and subsequent relaxation-inducing reuptake of $\mathrm{Ca}^{2+}$-ions from the cytosol agrees with the proteomic identification of a reduced abundance of key $\mathrm{Ca}^{2+}$-handling proteins (Doran et al. 2004; Matsumura et al. 2013). As shown in this report, abnormal $\mathrm{Ca}^{2+}$-homoestasis includes crucial regulators of the excitation-contraction-relaxation cycle, such as the core ryanodine receptor $\mathrm{Ca}^{2+}$-release channel of the sarcoplasmic reticulum, the $\alpha-1 S, \alpha-2 / \delta-1$ and $\beta$-1subunits of the voltage-dependent $\mathrm{Ca}^{2+}$-channel of the transverse tubules, the fast SERCA1 isoform of the $\mathrm{Ca}^{2+}$-ATPase of the longitudinal tubules, and the fast CSQ-1 and slow CSQ-2 isoforms of the luminal $\mathrm{Ca}^{2+}$-binding protein calsequestrin of the terminal cisternae region (Hernández-Ochoa and Schneider 2018).

In addition to proteomic changes in markers of the contractile apparatus, the cytoskeletal network and ion homeostasis, elevated levels of a variety of components involved in the maintenance and stabilisation of the extracellular matrix, protein synthesis, fibre remodelling and the immune response were also identified in this report. This included increases in various collagen chains, fibronectin, biglycan, the matricellular protein periostin and proteoglycans of the extracellular matrix, and probably relates to reactive myofibrosis in dystrophic muscles (Holland et al. 2016; Murphy et al. 2017), especially affecting the endomysium and causing loss of fibre elasticity and motor function (Desguerre et al. 2009). In agreement with the recent proteomic profiling of the dystrophin-deficient sarcolemma membrane (Murphy et al. 2019b), increased levels of subunits of the histocompatibility complex, macrophage mannose receptor and annexins were shown to occur in the dystrophic $m d x-4 c v$ diaphragm. The elevated concentration of the $\mathrm{Ca}^{2+}$-triggered phospholipidbinding isoform A1 of annexin is probably involved in plasmalemma wound-healing, but also in the restoration of cellular homeostasis by modulating the inflammatory response. This would agree with the concept that muscular dystrophy-specific inflammatory modifiers in the form of macrophages, neutrophils and T-lymphocytes amplify the degenerative phenotype in dystrophinopathies (Tidball et al. 2018). Differential effects on metabolic proteins were previously shown to occur in the $m d x$ mouse (Rayavarapu et al. 2013; Murphy et al. 2015b; Gamberi et al. 2018) and were also shown to be a feature of the $m d x$ - $4 c v$ diaphragm, including decreases in key enzymes of glucose metabolism, fatty acid transportation and oxidative metabolism, such as the NADH dehydrogenase complex.

\section{Conclusions}

Using an Orbitrap Fusion Tribrid mass spectrometer, the experimentally assessable proteome of the mouse diaphragm was established, with special focus on marker proteins of the acto-myosin apparatus and its auxiliary components, the dystrophin-glycoprotein complex and its associated extra-sarcomeric cytoskeletal network, the $\mathrm{Ca}^{2+}$-handling protein complex involved in the regulation of excitation-contraction coupling and muscle relaxation, and the extracellular matrix. The respiratory muscle proteome was shown to contain a characteristic presence of a wide variety of myosin heavy and lights chains, reflecting its specialized function in active inspiration. Standardized bioinformatics was employed to establish the distribution of protein classes within the normal diaphragm proteome, as well as biological processes and subcellular localization. The refined analysis of the $m d x-4 c v$ mouse model of X-linked muscular dystrophy revealed considerable changes in diaphragm-associated proteins involved in energy metabolism, the excitation-contraction-relaxation cycle, ion homeostasis, proteostasis, the cytoskeleton and the extracellular matrix. The pathoproteomic profile of the dystrophic diaphragm agrees with the idea that the almost complete loss of the membrane cytoskeletal protein dystrophin triggers complex changes in many key cellular processes, causing abnormal $\mathrm{Ca}^{2+}$-signalling, contractile weakness, sterile inflammation and reactive myofibrosis.

Acknowledgements Research was supported by project grants from Muscular Dystrophy Ireland and the Irish Health Research Board (HRB/MRCG-2016-20) and a Hume scholarship from Maynooth University. The Orbitrap Fusion Tribrid mass spectrometer was funded under a Science Foundation Ireland Infrastructure Award to Dublin City University (SFI 16/RI/3701). 


\section{References}

Agbulut O, Noirez P, Beaumont F, Butler-Browne G (2003) Myosin heavy chain isoforms in postnatal muscle development of mice. Biol Cell 95:399-406

Allen DG, Whitehead NP, Froehner SC (2016) Absence of dystrophin disrupts skeletal muscle signaling: roles of $\mathrm{Ca}^{2+}$, reactive oxygen species, and nitric oxide in the development of muscular dystrophy. Physiol Rev 96:253-305

Bordoni B, Zanier E (2013) Anatomic connections of the diaphragm: influence of respiration on the body system. J Multidiscip Healthc 6:281-291

Bradford MM (1976) A rapid and sensitive method for the quantitation of microgram quantities of protein utilizing the principle of protein-dye binding. Anal Biochem 72:248-254

Buu MC (2017) Respiratory complications, management and treatments for neuromuscular disease in children. Curr Opin Pediatr 29:326-333

Capitanio D, Moriggi M, Gelfi C (2017) Mapping the human skeletal muscle proteome: progress and potential. Expert Rev Proteomics 14:825-839

Carberry S, Zweyer M, Swandulla D, Ohlendieck K (2012) Proteomics reveals drastic increase of extracellular matrix proteins collagen and dermatopontin in the aged mdx diaphragm model of Duchenne muscular dystrophy. Int J Mol Med 30:229-234

Chapman VM, Miller DR, Armstrong D, Caskey CT (1989) Recovery of induced mutations for X chromosome-linked muscular dystrophy in mice. Proc Natl Acad Sci USA 86:1292-1296

Coirault C, Lambert F, Marchand-Adam S, Attal P, Chemla D, Lecarpentier Y (1999) Myosin molecular motor dysfunction in dystrophic mouse diaphragm. Am J Physiol 277:C1170-C1176

Coirault C, Pignol B, Cooper RN, Butler-Browne G, Chabrier PE, Lecarpentier Y (2003) Severe muscle dysfunction precedes collagen tissue proliferation in mdx mouse diaphragm. J Appl Physiol 94:1744-1750

Culligan K, Banville N, Dowling P, Ohlendieck K (2002) Drastic reduction of calsequestrin-like proteins and impaired calcium binding in dystrophic mdx muscle. J Appl Physiol 92:435-445

De Luca A, Pierno S, Camerino C, Huxtable RJ, Camerino DC (1998) Effect of taurine on excitation-contraction coupling of extensor digitorum longus muscle of dystrophic mdx mouse. Adv Exp Med Biol 442:115-119

Desguerre I, Mayer M, Leturcq F, Barbet JP, Gherardi RK, Christov C (2009) Endomysial fibrosis in Duchenne muscular dystrophy: a marker of poor outcome associated with macrophage alternative activation. J Neuropathol Exp Neurol 68:762-773

Deshmukh AS, Murgia M, Nagaraj N, Treebak JT, Cox J, Mann M (2015) Deep proteomics of mouse skeletal muscle enables quantitation of protein isoforms, metabolic pathways, and transcription factors. Mol Cell Proteom 14:841-853

Doran P, Dowling P, Lohan J, McDonnell K, Poetsch S, Ohlendieck $\mathrm{K}$ (2004) Subproteomics analysis of $\mathrm{Ca}^{2+}$-binding proteins demonstrates decreased calsequestrin expression in dystrophic mouse skeletal muscle. Eur J Biochem 271:3943-3952

Doran P, Martin G, Dowling P, Jockusch H, Ohlendieck K (2006) Proteome analysis of the dystrophin-deficient MDX diaphragm reveals a drastic increase in the heat shock protein cvHSP. Proteomics 6:4610-4621

Doran P, Wilton SD, Fletcher S, Ohlendieck K (2009) Proteomic profiling of antisense-induced exon skipping reveals reversal of pathobiochemical abnormalities in dystrophic mdx diaphragm. Proteomics 9:671-685

Dowling P, Murphy S, Ohlendieck K (2016) Proteomic profiling of muscle fibre type shifting in neuromuscular diseases. Expert Rev Proteom 13:783-799
Fuller HR, Graham LC, Llavero Hurtado M, Wishart TM (2016) Understanding the molecular consequences of inherited muscular dystrophies: advancements through proteomic experimentation. Expert Rev Proteom 13:659-671

Gamberi T, Fiaschi T, Valocchia E, Modesti A, Mantuano P, Rolland JF, Sanarica F, De Luca A, Magherini F (2018) Proteome analysis in dystrophic mdx mouse muscle reveals a drastic alteration of key metabolic and contractile proteins after chronic exercise and the potential modulation by anti-oxidant compounds. J Proteom 170:43-58

Geiger PC, Bailey JP, Mantilla CB, Zhan WZ, Sieck GC (2006) Mechanisms underlying myosin heavy chain expression during development of the rat diaphragm muscle. J Appl Physiol 101:1546-1555

Gonzalez-Freire M, Semba RD, Ubaida-Mohien Fabbri E, Scalzo P, Højlund K, Dufresne C, Lyashkov A, Ferrucci L (2017) The Human Skeletal Muscle Proteome Project: a reappraisal of the current literature. J Cachexia Sarcopenia Muscle 8:5-18

Greising SM, Medina-Martínez JS, Vasdev AK, Sieck GC, Mantilla CB (2015) Analysis of muscle fiber clustering in the diaphragm muscle of sarcopenic mice. Muscle Nerve 52:76-82

Guiraud S, Aartsma-Rus A, Vieira NM, Davies KE, van Ommen GJ, Kunkel LM (2015) The pathogenesis and therapy of muscular dystrophies. Annu Rev Genom Hum Genet 16:281-308

Henderson CA, Gomez CG, Novak SM, Mi-Mi L, Gregorio CC (2017) Overview of the muscle cytoskeleton. Compr Physiol 7:891-944

Hernández-Ochoa EO, Schneider MF (2018) Voltage sensing mechanism in skeletal muscle excitation-contraction coupling: coming of age or midlife crisis? Skelet Muscle 8:22

Højlund K, Yi Z, Hwang H, Lefort N, Flynn CR, Langlais P, Weintraub ST, Mandarino LJ (2008) Characterization of the human skeletal muscle proteome by one-dimensional gel electrophoresis and HPLC-ESI-MS/MS. Mol Cell Proteom 7:257-267

Holland A, Ohlendieck K (2013) Proteomic profiling of the contractile apparatus from skeletal muscle. Expert Rev Proteom 10:239-257

Holland A, Carberry S, Ohlendieck K (2013) Proteomics of the dystrophin-glycoprotein complex and dystrophinopathy. Curr Protein Pept Sci 14:680-697

Holland A, Dowling P, Meleady P, Henry M, Zweyer M, Mundegar RR, Swandulla D, Ohlendieck K (2015a) Label-free mass spectrometric analysis of the mdx-4cv diaphragm identifies the matricellular protein periostin as a potential factor involved in dystrophinopathy-related fibrosis. Proteomics 15:2318-2331

Holland A, Henry M, Meleady P, Winkler CK, Krautwald M, Brinkmeier H, Ohlendieck K (2015b) Comparative label-free mass spectrometric analysis of mildly versus severely affected $\mathrm{mdx}$ mouse skeletal muscles identifies annexin, lamin, and vimentin as universal dystrophic markers. Molecules 20:11317-11344

Holland A, Murphy S, Dowling P, Ohlendieck K (2016) Pathoproteomic profiling of the skeletal muscle matrisome in dystrophinopathy associated myofibrosis. Proteomics 16:345-366

Hopf FW, Turner PR, Steinhardt RA (2007) Calcium misregulation and the pathogenesis of muscular dystrophy. Subcell Biochem 45:429-464

Hor KN, Mah ML, Johnston P, Cripe TP, Cripe LH (2018) Advances in the diagnosis and management of cardiomyopathy in Duchenne muscular dystrophy. Neuromuscul Disord 28:711-716

Hussain SN, Cornachione AS, Guichon C, Al Khunaizi A, Leite Fde S, Petrof BJ, Mofarrahi M, Moroz N, de Varennes B, Goldberg P, Rassier DE (2016) Prolonged controlled mechanical ventilation in humans triggers myofibrillar contractile dysfunction and myofilament protein loss in the diaphragm. Thorax 71:436-445

Ishizaki M, Suga T, Kimura E, Shiota T, Kawano R, Uchida Y, Uchino K, Yamashita S, Maeda Y, Uchino M (2008) Mdx respiratory impairment following fibrosis of the diaphragm. Neuromuscul Disord 18:342-348 
Kanehisa M, Furumichi M, Tanabe M, Sato Y, Morishima K (2017) KEGG: new perspectives on genomes, pathways, diseases and drugs. Nucleic Acids Res 45(D1):D353-D361

Kelley RC, McDonagh B, Ferreira LF (2018) Advanced aging causes diaphragm functional abnormalities, global proteome remodeling, and loss of mitochondrial cysteine redox flexibility in mice. Exp Gerontol 103:69-79

Khirani S, Ramirez A, Aubertin G, Boulé M, Chemouny C, Forin V, Fauroux B (2014) Respiratory muscle decline in Duchenne muscular dystrophy. Pediatr Pulmonol 49:473-481

Kocjan J, Adamek M, Gzik-Zroska B, Czyżewski D, Rydel M (2017) Network of breathing. Multifunctional role of the diaphragm: a review. Adv Respir Med 85:224-232

Krüger M, Kötter S (2016) Titin, a central mediator for hypertrophic signaling, exercise-induced mechanosignaling and skeletal muscle remodeling. Front Physiol 7:76

Lieberman DA, Faulkner JA, Craig AB Jr, Maxwell LC (1973) Performance and histochemical composition of guinea pig and human diaphragm. J Appl Physiol 34:233-237

LoMauro A, D'Angelo MG, Aliverti A (2017) Sleep disordered breathing in duchenne muscular dystrophy. Curr Neurol Neurosci Rep 17:44

Matsumura CY, Taniguti AP, Pertille A, Santo Neto H, Marques MJ (2011) Stretch-activated calcium channel protein TRPC1 is correlated with the different degrees of the dystrophic phenotype in $\mathrm{mdx}$ mice. Am J Physiol Cell Physiol 301:C1344-C1350

Matsumura CY, Menezes de Oliveira B, Durbeej M, Marques MJ (2013) Isobaric tagging-based quantification for proteomic analysis: a comparative study of spared and affected muscles from mdx mice at the early phase of dystrophy. PLoS One 8(6):e65831

Mázala DA, Grange RW, Chin ER (2015) The role of proteases in excitation-contraction coupling failure in muscular dystrophy. Am J Physiol Cell Physiol 308:C33-C40

Mi H, Huang X, Muruganujan A, Tang H, Mills C, Kang D, Thomas PD (2017) PANTHER version 11: expanded annotation data from Gene Ontology and Reactome pathways, and data analysis tool enhancements. Nucleic Acids Res 45:D183-D189

Mizuno M (1991) Human respiratory muscles: fibre morphology and capillary supply. Eur Respir J 4:587-601

Muller J, Vayssiere N, Royuela M, Leger ME, Muller A, Bacou F, Pons F, Hugon G, Mornet D (2001) Comparative evolution of muscular dystrophy in diaphragm, gastrocnemius and masseter muscles from old male mdx mice. J Muscle Res Cell Motil 22:133-139

Murgia M, Nagaraj N, Deshmukh AS, Zeiler M, Cancellara P, Moretti I, Reggiani C, Schiaffino S, Mann M (2015) Single muscle fiber proteomics reveals unexpected mitochondrial specialization. EMBO Rep 16:387-395

Murphy S, Ohlendieck K (2015) The biochemical and mass spectrometric profiling of the dystrophin complexome from skeletal muscle. Comput Struct Biotechnol J 14:20-27

Murphy S, Ohlendieck K (2018) Proteomic profiling of large myofibrillar proteins from dried and long-term stored polyacrylamide gels. Anal Biochem 543:8-11

Murphy S, Henry M, Meleady P, Zweyer M, Mundegar RR, Swandulla D, Ohlendieck K (2015a) Simultaneous pathoproteomic evaluation of the dystrophin-glycoprotein complex and secondary changes in the mdx-4cv mouse model of duchenne muscular dystrophy. Biology (Basel) 4:397-423

Murphy S, Zweyer M, Mundegar RR, Henry M, Meleady P, Swandulla D, Ohlendieck K (2015b) Concurrent label-free mass spectrometric analysis of dystrophin isoform Dp427 and the myofibrosis marker collagen in crude extracts from mdx-4cv skeletal muscles. Proteomes 3:298-327

Murphy S, Dowling P, Ohlendieck K (2016) Comparative skeletal muscle proteomics using two-dimensional gel electrophoresis. Proteomes 4(3):E27

Murphy S, Brinkmeier H, Krautwald M, Henry M, Meleady P, Ohlendieck K (2017) Proteomic profiling of the dystrophin complex and membrane fraction from dystrophic mdx muscle reveals decreases in the cytolinker desmoglein and increases in the extracellular matrix stabilizers biglycan and fibronectin. J Muscle Res Cell Motil 38:251-268

Murphy S, Henry M, Meleady P, Ohlendieck K (2018) Utilization of dried and long-term stored polyacrylamide gels for the advanced proteomic profiling of mitochondrial contact sites from rat liver. Biol Methods Protoc 3(1):bpy008

Murphy S, Dowling P, Zweyer M, Swandulla D, Ohlendieck K (2019a) Proteomic profiling of giant skeletal muscle proteins. Expert Rev Proteom 16:241-256

Murphy S, Zweyer M, Henry M, Meleady P, Mundegar RR, Swandulla D, Ohlendieck K (2019b) Proteomic analysis of the sarcolemmaenriched fraction from dystrophic mdx-4cv skeletal muscle. J Proteom 191:212-227

O'Sullivan F, Keenan J, Aherne S, O'Neill F, Clarke C, Henry M, Meleady P, Breen L, Barron N, Clynes M, Horgan K, Doolan P, Murphy R (2017) Parallel mRNA, proteomics and miRNA expression analysis in cell line models of the intestine. World J Gastroenterol 23:7369-7386

Ohlendieck K, Swandulla D (2017) Molecular pathogenesis of Duchenne muscular dystrophy-related fibrosis. Pathologe 38:21-29

Parker KC, Walsh RJ, Salajegheh M, Amato AA, Krastins B, Sarracino DA, Greenberg SA (2009) Characterization of human skeletal muscle biopsy samples using shotgun proteomics. J Proteome Res 8:3265-3277

Petrof BJ, Stedman HH, Shrager JB, Eby J, Sweeney HL, Kelly AM (1993) Adaptations in myosin heavy chain expression and contractile function in dystrophic mouse diaphragm. Am J Physiol 265:C834-C841

Polla B, D’Antona G, Bottinelli R, Reggiani C (2004) Respiratory muscle fibres: specialisation and plasticity. Thorax 59:808-817

Rayavarapu S, Coley W, Cakir E, Jahnke V, Takeda S, Aoki Y, Grodish-Dressman H, Jaiswal JK, Hoffman EP, Brown KJ, Hathout Y, Nagaraju K (2013) Identification of disease specific pathways using in vivo SILAC proteomics in dystrophin deficient mdx mouse. Mol Cell Proteom 12:1061-1073

Santulli G, Lewis DR, Marks AR (2017) Physiology and pathophysiology of excitation-contraction coupling: the functional role of ryanodine receptor. J Muscle Res Cell Motil 38:37-45

Smith LR, Meyer G, Lieber RL (2013) Systems analysis of biological networks in skeletal muscle function. Wiley Interdiscip Rev Syst Biol Med 5:55-71

Sollanek KJ, Burniston JG, Kavazis AN, Morton AB, Wiggs MP, Ahn B, Smuder AJ, Powers SK (2017) Global proteome changes in the rat diaphragm induced by endurance exercise training. PLoS One 12:e0171007

Stedman HH, Sweeney HL, Shrager JB, Maguire HC, Panettieri RA, Petrof B, Narusawa M, Leferovich JM, Sladky JT, Kelly AM (1991) The mdx mouse diaphragm reproduces the degenerative changes of Duchenne muscular dystrophy. Nature 352:536-539

Szklarczyk D, Morris JH, Cook H, Kuhn M, Wyder S, Simonovic M, Santos A, Doncheva NT, Roth A, Bork P, Jensen LJ, von Mering C (2017) The STRING database in 2017: quality-controlled proteinprotein association networks, made broadly accessible. Nucleic Acids Res 45:D362-D368

Tidball JG, Welc SS, Wehling-Henricks M (2018) Immunobiology of inherited muscular dystrophies. Compr Physiol 8:1313-1356

Wiśniewski JR, Zougman A, Nagaraj N, Mann M (2009) Universal sample preparation method for proteome analysis. Nat Methods 6:359-362

Publisher's Note Springer Nature remains neutral with regard to jurisdictional claims in published maps and institutional affiliations. 